\title{
The Beijing Climate Center atmospheric general circulation model: description and its performance for the present-day climate
}

\author{
Tongwen Wu · Rucong Yu • Fang Zhang · Zaizhi Wang • Min Dong • \\ Lanning Wang · Xia Jin · Deliang Chen · Laurent Li
}

Received: 4 July 2008/ Accepted: 24 October 2008/Published online: 2 December 2008

(C) The Author(s) 2008. This article is published with open access at Springerlink.com

\begin{abstract}
The Beijing Climate Center atmospheric general circulation model version 2.0.1 (BCC_AGCM2.0.1) is described and its performance in simulating the present-day climate is assessed. BCC_AGCM2.0.1 originates from the community atmospheric model version 3 (CAM3) developed by the National Center for Atmospheric Research (NCAR). The dynamics in BCC_AGCM2.0.1 is, however, substantially different from the Eulerian spectral formulation of the dynamical equations in CAM3, and several new physical parameterizations have replaced the corresponding original ones. The major modification of the model physics in BCC_AGCM2.0.1 includes a new convection scheme, a dry adiabatic adjustment scheme in which potential temperature is conserved, a modified scheme to calculate the
\end{abstract}

T. Wu $\cdot$ F. Zhang $\cdot$ Z. Wang $\cdot$ M. Dong $\cdot$ L. Wang $\cdot$ X. Jin $\cdot$

D. Chen $\cdot$ L. Li

Beijing Climate Center, China Meteorological Administration, Beijing, People's Republic of China

R. Yu

China Meteorological Administration,

Beijing, People's Republic of China

D. Chen

Department of Earth Sciences, University of Gothenburg,

Gothenburg, Sweden

L. Li

Laboratoire de Météorologie Dynamique,

IPSL, CNRS/UPMC, Paris, France

T. Wu $(\square)$

National Climate Center, China Meteorological Administration, 46 Zhongguancun Nandajie, 100081 Beijing,

People's Republic of China

e-mail: twwu@cma.gov.cn sensible heat and moisture fluxes over the open ocean which takes into account the effect of ocean waves on the latent and sensible heat fluxes, and an empirical equation to compute the snow cover fraction. Specially, the new convection scheme in BCC_AGCM2.0.1, which is generated from the Zhang and McFarlane's scheme but modified, is tested to have significant improvement in tropical maximum but also the subtropical minimum precipitation, and the modified scheme for turbulent fluxes are validated using EPIC2001 in situ observations and show a large improvement than its original scheme in CAM3. BCC_AGCM2.0.1 is forced by observed monthly varying sea surface temperatures and sea ice concentrations during 1949-2000. The model climatology is compiled for the period 1971-2000 and compared with the ERA-40 reanalysis products. The model performance is evaluated in terms of energy budgets, precipitation, sea level pressure, air temperature, geopotential height, and atmospheric circulation, as well as their seasonal variations. Results show that BCC_AGCM2.0.1 reproduces fairly well the present-day climate. The combined effect of the new dynamical core and the updated physical parameterizations in BCC_AGCM2.0.1 leads to an overall improvement, compared to the original CAM3.

Keywords BCC_AGCM2.0.1 - CAM3 - Performance · Present climate $\cdot$ ERA-40 reanalysis

\section{Introduction}

Beijing Climate Center (BCC) is based on the National Climate Center (NCC) at China Meteorological Administration (CMA) and has severed as a Regional Climate Center (RCC) of World Meteorological Organization (WMO) in Asia since 2007. BCC is an operational and 
research center and devoted to global and regional climate monitoring, diagnostics and predictions. All these activities demand numerical models, in particular, an atmospheric general circulation model (AGCM). The development of such a model started almost immediately after the establishment of the NCC in the middle 1990s. The first version of the BCC-AGCM (BCC_AGCM1.0) was adapted from a medium-range numerical weather forecasting model used at the National Meteorological Center, CMA (Dong 2001), which in turn could be traced back to the European Centre for medium-range weather forecasts (ECMWF) AGCM (Hollingsworth et al. 1980; Jarraud et al. 1985). BCC_AGCM1.0 was running with the horizontal resolution of T63 (approximately $1.875^{\circ}$ latitude $\times 1.875^{\circ}$ longitude) and 16 hybrid P- $\sigma$ layers in the vertical. BCC_AGCM1.0 was also coupled with an ocean model (Jin et al. 1999; Yu and Zhang 1998), which forms the basis of BCC_CM1.0 (Ding et al. 2004). The latter, as a component of the operational short-term climate prediction system, had been applied to the operational services of climate prediction on monthly, seasonal and annual scales since 2002 (Ding et al. 2002, 2004; Li et al. 2005). Its prediction proves to be useful in terms of societal and economic benefits judging from the forecasting results during the trial period from 2002 to 2004 (Zhang et al. 2004a).

Advances in our understanding of the climate system, together with the need to reduce the uncertainties associated with predictions of future climate change, require that global climate models represent the physical processes with increasing levels of complexity. BCC_CM1.0 is outdated in terms of the represented scientific knowledge and can thus not meet the increasing demand for operational climate prediction and climate projection under global warming context. An initiative to develop a new generation of climate system model was launched in the CMA with an implementation plan focused on a new generation of the atmospheric component.

Because the programming structure in the current BCC_AGCM1.0 does not match the rapid development of computing technology, the second generation of BCCAGCM is not a simple evolution of the current model. It is rather based on a widely used framework - the Community Atmosphere Model version 3 (CAM3), developed in NCAR with a better consideration of the parallel computing architectures. The dynamic core of the CAM3 was from a traditional Eulerian spectral formulation of the governing equations. Wu et al. (2008) demonstrated that the use of a reference atmosphere can substantially improve the calculation of pressure gradient force and thus model performance at regional and global scales, especially for the tropospheric temperature and winds.

Climate model development carries with it the requirement for evaluation of all aspects of the simulated climate. For example, a validation of the simulated mean climatology and the spatial and temporal variability can reveal model's systematic errors. The validation also provides useful information to interpretation and application of the predictions made using the model. The purpose of this paper is twofold. The first deals with documenting the key aspects of the changes in the model dynamics and physics of BCC_AGCM2.0.1, while the second focuses on evaluating performance of BCC_AGCM2.0.1, in comparison to CAM3, in simulating the present-day climate. The paper is arranged as follows: Sect. 2 provides a simple description of the major features of the model dynamics and physics including the modified schemes; Sect. 3 presents the results from the experiment designed for the model assessment with help of observations; and Sect. 4 shows a summary of the most important results and some conclusions.

\section{Model description}

\subsection{Dynamics}

The dynamical core of the model is described in $\mathrm{Wu}$ et al. (2008). The model equations are formulated in a horizontal T42 spectral resolution (approximately $2.8^{\circ}$ latitude $\times 2.8^{\circ}$ longitude grid) and a terrain-following hybrid vertical coordinate with 26 levels and a rigid lid at $2.914 \mathrm{mb}$. They are originated from the Eulerian dynamic framework of CAM3. Main differences lie in the use of a reference atmospheric temperature and a reference surface pressure in BCC_AGCM2.0.1, which induces substantial changes in the associated diagnostic equations and their resolving technique. While the details of the reference temperature and pressure and their impact are discussed in Wu et al. (2008), a brief description is given below.

The stratified reference atmospheric $\bar{T}(p)$ and reference geopotential height $\bar{\phi}(p)$ in BCC_AGCM2.0.1 are given as $\bar{T}(p) \equiv p \cdot\left[a_{T}+b_{T} \cdot e^{c_{T} \ln p}\right]$,

$\bar{\phi}(p) \equiv-R \cdot\left[a_{T}\left(p-p_{\mathrm{s} 0}\right)+\frac{b_{T}}{\left(1+c_{T}\right)} e^{\left(1+c_{T}\right) \ln \left(p / p_{\mathrm{s} 0}\right)}\right]$

where $\quad a_{T}=0.09923 \mathrm{~K} \mathrm{mb}^{-1}, b_{T}=247.7874 \mathrm{~K} \mathrm{mb}^{-1}$, $c_{T}=-1.0385$, and $p_{\mathrm{s} 0}=1013 \mathrm{hPa} . R$ is the gas constant for dry air. $\bar{T}(p)$ and $\bar{\phi}(p)$ meet the hydrostatic balance

$\frac{\partial \bar{\phi}}{\partial \ln p}=-R \bar{T}$.

The vertical profile $\bar{T}(p)$ approximately represents that of the US middle-latitude standard atmosphere. The reference surface pressure $\bar{p}_{\mathrm{s}}$ is also introduced as 
$\bar{\Pi}(\lambda, \varphi) \equiv \ln \left(\bar{p}_{\mathrm{s}}\right)=-\frac{\phi_{\mathrm{s}}}{R T_{\mathrm{s}}^{r}}+\ln \left(p_{\mathrm{s} 0}\right)$,

where $\phi_{\mathrm{s}}$ is the surface geopotential, $T_{\mathrm{s}}^{r}$ a constant (273 K), and $p_{\mathrm{s} 0}$ reference sea level pressure (SLP) $(1,000 \mathrm{hPa})$. Then, we define the perturbations of temperature $T$, virtual temperature $T_{\mathrm{v}}$, geopotential $\phi$, and surface pressure $\Pi \equiv$ $\ln \left(p_{\mathrm{s}}\right)$ from $\bar{T}(p), \bar{\phi}(p)$, or $\bar{\Pi}(\lambda, \varphi)$ as

$$
\begin{aligned}
& T_{\mathrm{v}}(\lambda, \varphi, \eta) \equiv \bar{T}(p)+T_{\mathrm{v}}^{\prime}(\lambda, \varphi, \eta) \\
& T(\lambda, \varphi, \eta) \equiv \bar{T}(p)+T^{\prime}(\lambda, \varphi, \eta) \\
& \phi(\lambda, \varphi, \eta) \equiv \bar{\phi}(p)+\phi^{\prime}(\lambda, \varphi, \eta) \\
& \Pi(\lambda, \varphi) \equiv \bar{\Pi}(\lambda, \varphi)+\Pi^{\prime}(\lambda, \varphi) .
\end{aligned}
$$

In BCC_AGCM2.0.1, prognostic variables for the temperature and surface pressure are replaced by their perturbations from the prescribed references.

The numerical algorithms of the explicit time difference scheme for vorticity and the semi-implicit time difference scheme for divergence, perturbation temperature, and perturbation surface pressure equation are given in $\mathrm{Wu}$ et al. (2008). The time step is $20 \mathrm{~min}$. The methodology implemented in BCC_AGCM2.0.1 improves the description of the vertical structure of temperature for uneven vertical discretization, transform the calculation of pressure gradient force from a subtraction of two large terms into a sum of two small terms, and also reduces the truncation error in calculating the surface pressure and the derivative of surface pressure with longitude and latitude.

The solutions of prognostic equations for vorticity, divergence, temperature, and surface pressure in the dynamic core of BCC_AGCM2.0.1 are evidently different from those in CAM3. However, BCC_AGCM2.0.1 still keeps some algorithmic approaches used by CAM3 including the semi-implicit scheme for the horizontal diffusion process, the use of the semi-Lagrangian advection transport scheme for the water vapor as well as tracers, the spectral transform method for treating the dry dynamics, the recursive time filter, and the three-time-level "process split" coupling manner dealing with the dynamical process and physical parameterization.

\subsection{Physical processes}

In BCC_AGCM2.0.1, most of the model physical processes are still based on the CAM3 physics package, as described in Collins et al. (2004, 2006), but the following new or modified parameterization schemes are implemented to replace the corresponding original schemes.

\subsubsection{Convection}

A revised Zhang and McFarlane's convection scheme (Zhang and Mu 2005a, hereafter RZM) is further modified and incorporated into the model to replace the original scheme of Zhang and McFarlane (1995, hereafter ZM) scheme in CAM3. In comparison to the ZM scheme, the large difference in the RZM scheme is the closure condition. In the ZM scheme, it is assumed that convection acts to remove the atmospheric convective available potential energy with a relaxation time of $2 \mathrm{~h}$ and the cloud-base mass flux is proportional to the amount of convective available potential energy (CAPE) in the atmosphere. The RZM scheme assumes that an quasi-equilibrium exists between convection and the large-scale environment in the free troposphere above the boundary layer. The cloud-base mass flux is determined by the large-scale destabilization of the free troposphere due to the free tropospheric temperature and moisture changes caused by large-scale processes. The second modification in RZM scheme is the inclusion of a relative humidity threshold $\left(\mathrm{RH}_{c}\right)$ in the scheme as a convection trigger to suppress spurious convection in situations when the boundary layer air is dry. The relative humidity of the air at the level where the parcels are lifted must be greater than $75 \%$ ( $80 \%$ is the initially suggested threshold) to trigger convection. Besides this relative humidity condition, other conditions also need to be satisfied to trigger deep convection: both CAPE and the CAPE generation by large-scale processes should be positive. The third modification in RZM scheme is that the bottom of the unstable lifted layer is allowed to occur above the boundary layer, while in the ZM scheme this level is limited to below the top of the boundary layer. The modification in RZM scheme leads to significant improvement in the rainfall simulation of the tropical climate and its intraseasonal variability (Zhang and Mu 2005a, b).

Beyond the RZM scheme, we implemented two additional modifications in BCC_AGCM2.0.1 (hereafter MRZM scheme): (a) in addition to all other convection triggering conditions, we assume that the pressure vertical velocity $\omega$ at the level where the parcels are lifted must be less than zero and the relative humidity is higher than $75 \%$. This modification intends to take into account the fact that cumulus convection commonly goes along with the compensating convergence upward motion in the bottom of the convection cloud. (b) The conversion coefficient $c_{0}$ from cloud water to rain water is adjusted from its original value of $c_{0}=3 \times 10^{-3} \mathrm{~m}^{-1}$ to a new value of $c_{0}=1.5 \times 10^{-3} \mathrm{~m}^{-1}$, with the conversion equation given by

$\rho P_{\mathrm{u}}=c_{0} M_{\mathrm{u}} l$ 
Fig. 1 Zonally averaged annual (a), DJF (b), and JJA (c) precipitation climatology of the AMIP-like 30-year simulations of 19712000 from BCC_AGCM2.0.1 separately using Zhang and McFarlane (1995) cumulus convective scheme (ZM95 in line legends), its revised scheme (RZM, Zhang and Mu 2005a), and the modified RZM scheme (MRZM) in this work but keeping all the physical processes in the same, and the CMAP observation. Units: $\mathrm{mm} \mathrm{day}^{-1}$

where $M_{\mathrm{u}}$ is the cloud updraft mass flux and $l$ the cloud liquid water.

The use of MRZM scheme in BCC_AGCM2.0.1 leads to reduction of the intensity of precipitation. We tested the different influences on the precipitation simulations using ZM95, RZM, and MRZM schemes but keeping all others the same in BCC_AGCM2.0.1 which is forced by observed monthly varying sea surface temperatures and sea ice concentrations during 1949-2000. The details about the forcing data will be given in Sect. 3.1 of this paper. Figure 1 shows the simulated climatology for zonally averaged annual, seasonal precipitation rates using different cumulus convective schemes. The model climatology is compiled for the period 1971-2000 and compared with the ERA-40 reanalysis products. As shown in Fig. 1, large divergences of precipitation for different cumulus schemes are evident in the middle and low latitudes between $60^{\circ} \mathrm{S}$ and $60^{\circ} \mathrm{N}$. With contrast to ZM95 and RZM schemes, the MRZM scheme improves not only the southern tropical maximum and the northern subtropical minimum in December-January-February (DJF) mean, but also the precipitation in both hemispheric tropics and the northern subtropical latitudes in June-July-August (JJA) mean. The MRZM scheme in BCC_AGCM2.0.1 also captures more reasonable regional distribution of precipitation especially over the Southern Pacific Convergence Zone (SPCZ) in DJF and the western tropical Pacific in JJA, and seasonal south-north March of zonally averaged precipitation (not shown). Although the annual mean precipitation with the MRZM scheme is further below the CMAP in the tropics than those with the other two schemes, it is much close to and even slightly larger than the precipitation from Global Precipitation Climatology Project (GPCP) in tropics (omitted). The remarkable improvement in the annual mean precipitation in lower latitudes shows that the implementation of the MRZM scheme in BCC_ AGCM2.0.1 was a good choice.

\subsubsection{Dry adiabatic adjustment}

The new dry adiabatic adjustment is originated from the scheme suggested by Yan (1987). With the assumption of hydrostatic balance, there is
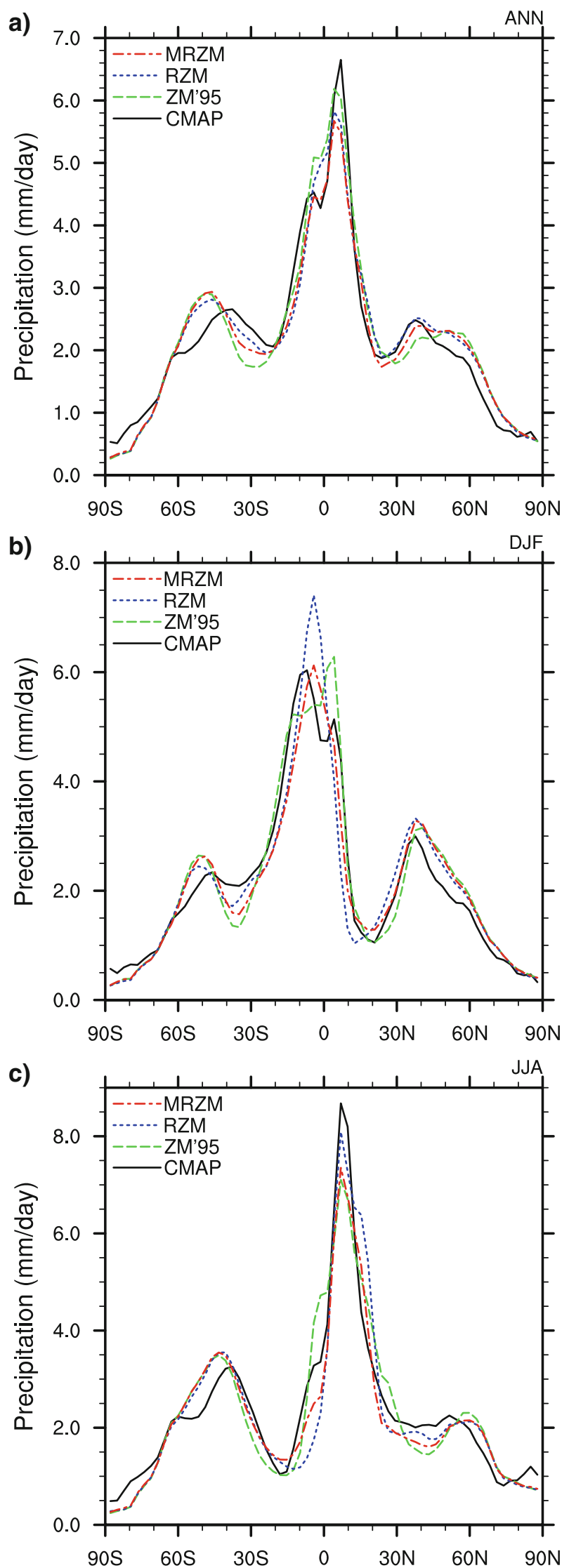
$\frac{\partial \ln \theta}{\partial \ln p}=-\frac{R}{g}\left(\frac{\partial T}{\partial \ln p}-\frac{g}{c_{p}}\right)$.

Dry-convective adjustment occurs if the temperature lapse rate between any two adjacent layers is absolutely unstable, that is, exceeds the dry adiabatic lapse rate,

$\frac{\partial \ln \theta}{\partial \ln p}>\frac{R}{g} C_{\gamma}$

or

$\frac{\partial T}{\partial \ln p}>\bar{T}\left(\frac{R}{g} C_{\gamma}+\frac{R}{C_{p}}\right)$.

where $C \gamma=\left(\frac{\partial \bar{T}}{\partial \ln p}\right)_{c}-\frac{g}{c_{p}}$ in which $\left(\frac{\partial \bar{T}}{\partial \ln p}\right)_{c}$ is the critical value of the temperature lapse rate for stable state. In general, $C_{\gamma}$ has the order of $10^{-3}$ to $10^{-4} \mathrm{~K} \mathrm{~m}^{-1}$. If $C_{\gamma}=-0.5 \times 10^{-3} \mathrm{~K} \mathrm{~m}^{-1}$ (Yan 1987), the frequency for dry adiabatic adjustment can be decreased. This choice of slightly negative value accounts for the typical observed state of the convectively active boundary layer (statically neutral or slightly stable vertical stratification except in a shallow surface layer). $g$ is acceleration due to gravity, $\theta$ potential temperature, $T$ temperature, and $p$ pressure. If this occurs, the instability is instantaneously removed by adjusting the temperatures of the two layers such that their lapse rate is the dry adiabatic one. The adjusted temperature $\hat{T}$ meets that

$\frac{\partial \hat{T}}{\partial \ln p}=\overline{(\hat{T})} \cdot\left(\frac{R}{g} C_{\gamma}+\frac{R}{C_{p}}\right)$

where $\overline{(\hat{T})}$ is the mean temperature between the two adjacent layers after adjustment. This is done under the constraint that the total potential temperature $\theta$ for all of the dry adiabatic unstable layers is conserved, that is

$\sum_{k} \Delta \theta_{k} \Delta p_{k}=0$

in which $\Delta \theta_{k}=\hat{\theta}_{k}-\theta_{k}$ is the difference of the two potential temperatures at model layer $k$ after and before the dry adjustment.

The adjusted amount of humidity along with the dry adiabatic adjustment for temperature is conserved and depends on the mixed air mass caused by the temperature adjustment.

\subsubsection{Turbulent fluxes over ocean surface}

Bulk formulas are used to determine the turbulent fluxes of momentum, latent heat ( $\mathrm{LH})$ and sensible heat $(\mathrm{SH})$ between the atmosphere and the ocean in CAM3 (Collins et al. 2004). In BCC_AGCM2.0.1, we keep the original scheme of bulk formulas, but the roughness lengths for momentum $z_{0}$, heat $z_{0 \mathrm{~h}}$ and evaporation $z_{0 q}$ are calculated as suggested by Smith (1989), $z_{0}=\alpha \frac{u_{*}^{2}}{g}+r \frac{v}{u_{*}}$

$z_{0 \mathrm{~h}}=0.4 \frac{v}{u_{*}}$

$z_{0 q}=0.62 \frac{v}{u_{*}}$

where $u_{*}$ is the friction velocity and $g$ the acceleration of gravity. $v=1.4 \times 10^{5} \mathrm{~m}^{2} \mathrm{~s}^{-1}$ is the kinematic viscosity of air. Zeng et al. (1998) obtained $\alpha=0.013$ and $r=0.11$ by using observations from TOGA-COARE.

In BCC_AGCM2.0.1, we parameterize also other phenomena such as waves and sea spray exerting influences on surface latent and sensible heat fluxes through their effects on air temperature and humidity. Both theory and observation suggest that, at high wind speeds, evaporation from sea spray is significant (Bao et al. 2000). When the wind speed is in excess of approximately $15 \mathrm{~m} \mathrm{~s}^{-1}$, a substantial amount of sea spray is produced by breaking waves, bursting bubbles, and wind gusts (e.g., Kraus and Businger 1994).

In BCC_AGCM2.0.1, the influence of the wind speed on waves and sea spray and then on the surface fluxes is formulated by

$\Delta \theta=\left(\theta_{\mathrm{A}}-T_{\mathrm{s}}\right) \cdot f\left(U_{\mathrm{A}}\right)$

$\Delta q=\left(q_{\mathrm{A}}-q_{\mathrm{s}}\right) \cdot f\left(U_{\mathrm{A}}\right)$

where $U_{\mathrm{A}}$ is the wind at the lowest level and $f\left(U_{\mathrm{A}}\right)$ is an empirical function and given as

$f\left(U_{\mathrm{A}}\right)= \begin{cases}\exp \left(\frac{5-U_{\mathrm{A}}}{40}\right), & \text { for } U_{\mathrm{A}} \geq 5 \mathrm{~m} / \mathrm{s} \\ 1, & \text { for } U_{\mathrm{A}}<5 \mathrm{~m} / \mathrm{s}\end{cases}$

This differs from the original scheme of CAM3 which calculated the potential temperature difference as $\Delta \theta=\theta_{\mathrm{A}}-T_{\mathrm{s}}$ in which $T_{\mathrm{s}}$ is the surface temperature, and the specific humidity difference $\Delta q=q_{\mathrm{A}}-q_{\mathrm{s}}\left(T_{\mathrm{s}}\right)$ where $q_{\mathrm{s}}\left(T_{\mathrm{s}}\right)$ is the saturation specific humidity at the sea surface temperature. $q_{\mathrm{A}}$ and $\theta_{\mathrm{A}}$ are the lowest level atmospheric humidity and potential temperature, respectively. The application of an empirical function $f\left(U_{\mathrm{A}}\right)$ in Eqs. 18 and 19 is based on the consideration that the sea waves and spray cause the atmosphere wetter and then weaken the humidity difference $\Delta q$ and temperature difference $\Delta \theta$.

The modification for turbulent fluxes in ocean surface may improve the simulations. The in situ observations of the atmospheric boundary layer (ABL) during the September-October 2001 field campaign of the Eastern Pacific Investigation of Climate (EPIC2001, Weller et al. 1999) provides an opportunity to examine the influence of this modified scheme used in BCC_AGCM2.0.1 on the simulations of wind stress, and latent and sensible heat 
Fig. 2 Scatterplots of the EPIC2001 observations of wind stress (top), sensible heat flux (middle), and latent heat flux (bottom) versus the simulations using the modified scheme in BCC_AGCM2.0.1 (left panel) and the original scheme in CAM3 (right panel)
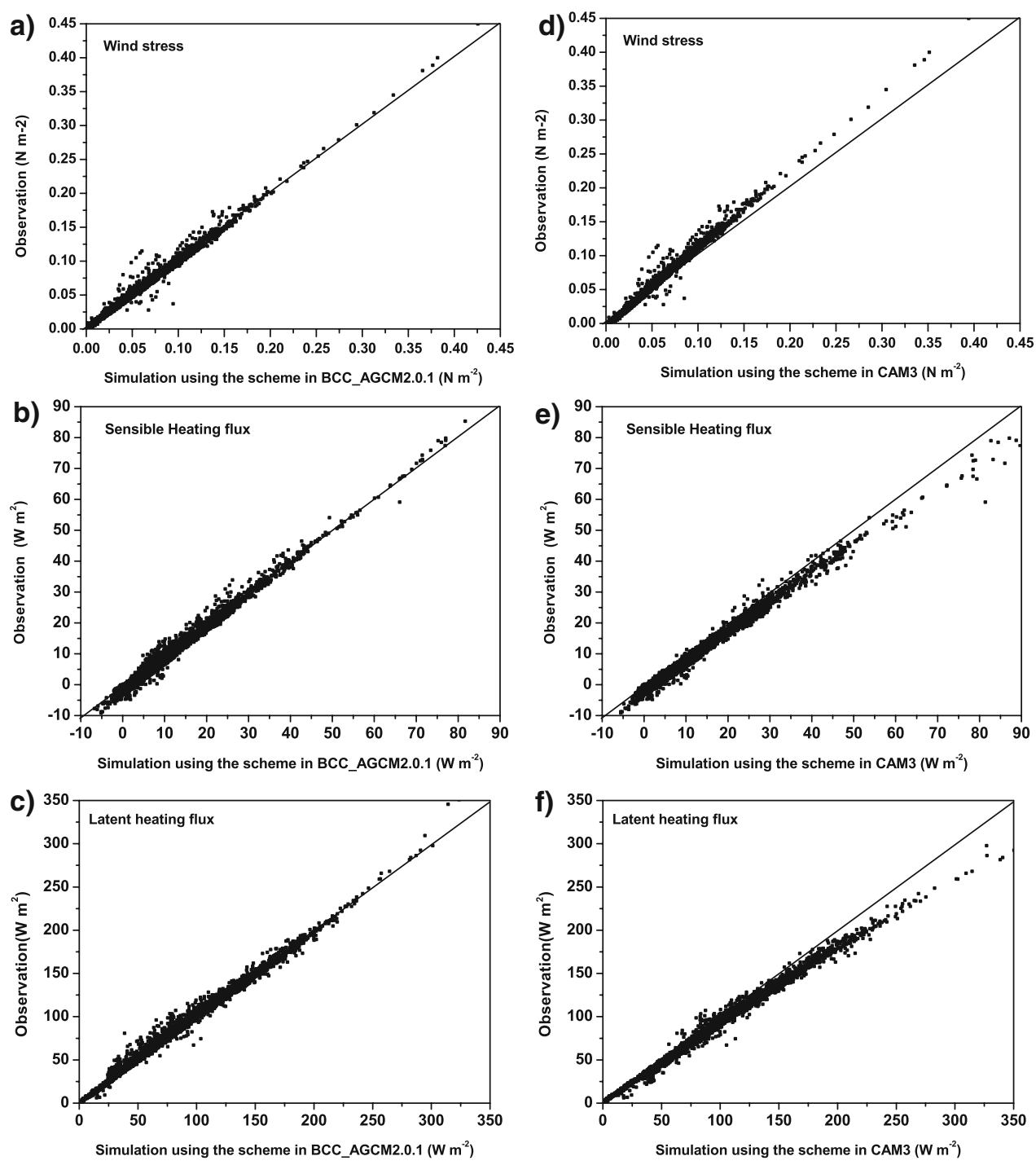

flux. The data were collected for a vertical-meridional cross section along $95^{\circ} \mathrm{W}$ and between the equator and $12^{\circ} \mathrm{N}$. In the EPIC domain, with its strong atmosphereocean interactions, moored buoys such as upgraded TAO or IMET buoys, provide continuous measurement of surface fluxes of latent and sensible heat and radiation, rainfall rate, SST, and other surface meteorological conditions.

Figure 2 shows the scatterplots of the observed EPIC2001 wind stress, sensible heat flux, and latent heat flux against the corresponding simulations from the modified scheme used in BCC_AGCM2.0.1 and the original scheme in CAM3. The scheme in CAM3 underestimates the wind stress but overestimates the sensible heat and latent heat fluxes. The greater the fluxes are, the larger the biases. These systematic errors are obviously reduced when the modified scheme is used.

\subsubsection{Snow cover fraction parameterization}

BCC_AGCM2.0.1, as in CAM3, incorporates the community land model version 3 (CLM3) which is detailed in Oleson et al. (2004).

The snow cover fraction $\left(f_{\text {sno }}\right)$ is an important factor in calculating ground albedo over the snow-covered surface. When snow pack is patchy on the ground, the domainaveraged direct beam $\alpha_{\mathrm{g}, \wedge}^{\mu}$ and diffuse $\alpha_{\mathrm{g}, \wedge}$ ground albedos are usually taken as a weighted mean of the albedos over "soil" and snow

$\alpha_{\mathrm{g}, \wedge}^{\mu}=\alpha_{\mathrm{soil}, \wedge}^{\mu}\left(1-f_{\mathrm{sno}}\right)+\alpha_{\mathrm{sno}, \wedge}^{\mu} f_{\mathrm{sno}}$

$\alpha_{\mathrm{g}, \wedge}=\alpha_{\mathrm{soil}, \wedge}\left(1-f_{\mathrm{sno}}\right)+\alpha_{\mathrm{sno}, \wedge} f_{\mathrm{sno}}$

Since snow albedo is much higher than those of soil and vegetation, overestimation (underestimation) of snow cover fraction will result in higher (lower) surface 
albedo. Correct estimation of snow cover fraction in a grid square of a GCM becomes essential for the calculation of the surface energy balance and for the model performance (Foster et al. 1996).

In CAM3, the original method of CLM3 in obtaining the snow cover fraction was

$f_{\mathrm{sno}}=\frac{h_{\mathrm{sno}}}{10 z_{0 m, \mathrm{~g}}+h_{\mathrm{sno}}}$,

where $h_{\text {sno }}$ is the domain-averaged depth of snow (m), and $z_{0 m, \mathrm{~g}}=0.01 \mathrm{~m}$ is the momentum roughness length for soil. However, there is not a uniform formula suitable for GCMs to compute snow cover fraction (Wu and $\mathrm{Wu}$ 2004). BCC_ AGCM2.0.1 uses another method obtained empirically by $\mathrm{Wu}$ and $\mathrm{Wu}$ (2004), and based on satellite observations:

$f_{\mathrm{sno}}=\min \left(\frac{b \cdot h_{\mathrm{sno}}}{h_{\mathrm{sno}}+a}, 1\right)$

where $a$ is a constant $(10.6 \mathrm{~cm}) . b$ is a non-dimensional coefficient and depends on the horizontal GCM grid resolution. We used $b=1.66$ in BCC_AGCM2.0.1 for T42 resolution.

\section{Evaluation of simulated climatology}

\subsection{Experiment design and data used in evaluation}

The evaluation of BCC_AGCM2.0.1 is made through integrations of the model with, as boundary conditions, the observed sea surface temperature (SST) and sea ice concentrations for the period 1950-2000. The SST and sea ice datasets are blended products that combine the global Hadley Centre Sea Ice and Sea Surface Temperature (HadISST) dataset (Rayner et al. 2003) for years up to 1981 and the Reynolds et al. (2002) dataset after 1981. A fivemember ensemble of runs was performed to produce a reliable climatology. In these runs, the concentrations of greenhouse gases are held constant at their levels of 1990. In the default configuration of both BCC_AGCM2.0.1 and CAM3, the radiative effects of a climatological aerosol dataset are taken into account in the calculation of shortwave fluxes and heating rates. The aerosol dataset includes the monthly mean annual cycle of sulfate, sea salt, carbonaceous, and soil-dust aerosols. The climatology is derived from a chemical transport model constrained by assimilation of satellite retrievals of aerosol depth for the period 1995-2000 (Collins et al. 2006).

For the purpose of comparison, the original CAM3 model was run with the exact protocol as described above for BCC_AGCM2.0.1. The last 30 years (1971-2000) of the two models are analyzed for validation against observational and reanalysis climatologies.
The primary source of the validation data is the ERA-40 (Kållberg et al. 2004). Seasonal-mean climatologies are first constructed, and then regridded to the T42 spectral resolution to ease the comparison with the model-generated, pressure-interpolated fields. Other datasets used for validation include the Climate Prediction Center (CPC) merged analysis of precipitation (CMAP) (Xie and Arkin 1996) and earth radiation budget experiment (ERBE) data for radiation budget at the top of the atmosphere (Kiehl and Trenberth 1997), the cloud data from International Satellite Cloud Climatology Project (ISCCP) (Rossow and Schiffer 1999) and the moderate resolution imaging spectroradiometer (MODIS) (King et al. 2003), and total column (integrated) water vapor data sets during 1988-2001 from the Water Vapor Project (NVAP) (Randel et al. 1996).

\subsection{Model evaluation}

\subsubsection{Global statistics}

Table 1 presents the global annual mean climatological properties from the BCC_AGCM2.0.1, CAM3, and the corresponding estimates from observations. In comparison to the CAM3 results, the significant improvement in BCC_AGCM2.0.1 model is the radiative budget at the top of the atmosphere. The absorbed solar radiation of $232.026 \mathrm{~W} \mathrm{~m}^{-2}$ from the BCC_AGCM2.0.1 is in close agreement with the ERBE estimate of $234.0 \mathrm{~W} \mathrm{~m}^{-2}$ and there is only an underestimation of $2.0 \mathrm{~W} \mathrm{~m}^{-2}$ in the model. The outgoing longwave radiation $\left(232.1 \mathrm{~W} \mathrm{~m}^{-2}\right)$ is also underestimated by $1.9 \mathrm{~W} \mathrm{~m}^{-2}$ compared to the ERBE data $\left(234.0 \mathrm{~W} \mathrm{~m}^{-2}\right)$. Thus, it nearly balances the absorbed solar radiation.

As shown in Table 1, the longwave and shortwave cloud radiative forcings in both BCC_AGCM2.0.1 and CAM3 are close to the ERBE data, although the simulated highcloud and low-cloud amounts are obviously much higher than the ISCCP data. The total cloud liquid water path is also too thick compared to that deduced from the MODIS data. The large biases of high cloud and low cloud are believed to be attributable to the cloud parameterization scheme which is identical in BCC_AGCM2.0.1 and CAM3 models. It also needs to be kept in mind that large uncertainties may exist in observational estimate of cloud properties.

At the surface, the absorbed solar radiation from BCC_AGCM2.0.1 is $11.0 \mathrm{~W} \mathrm{~m}^{-2}$ less than the ISCCP estimation. This model bias is mostly attributed to the underestimation of the all-sky surface insolation in the polar and tropical regions (Fig. 3). As shown in Fig. 3, the same also occurs in CAM3. Nevertheless, a net radiative budget of $99.0 \mathrm{~W} \mathrm{~m}^{-2}$ in BCC_AGCM2.0.1 at the surface is still in close agreement with the observational data of 
Table 1 Global annual mean climatological properties for BCC_AGCM2.0.1 and CAM3

\begin{tabular}{|c|c|c|c|}
\hline Property & Observation & BCC_AGCM2.0.1 & CAM3 \\
\hline \multicolumn{4}{|l|}{ Top of atmosphere } \\
\hline Energy budget ( $\mathrm{W} \mathrm{m}^{-2},+$ upward $)$ & & 0.114 & -2.482 \\
\hline Absorbed solar radiation $\left(\mathrm{W} \mathrm{m}^{-2}\right)$ & $234.004^{\mathrm{a}}$ & 232.026 & 237.094 \\
\hline Outgoing longwave radiation $\left(\mathrm{W} \mathrm{m}^{-2}\right)$ & $233.946^{\mathrm{a}}$ & 232.140 & 234.612 \\
\hline \multicolumn{4}{|l|}{ Surface fluxes } \\
\hline Surface energy budget $\left(\mathrm{W} \mathrm{m}^{-2}\right)$ & & 1.008 & 0.513 \\
\hline Net solar radiation $\left(\mathrm{W} \mathrm{m}^{-2}\right)$ & $168^{\mathrm{b}}, 165.9^{1}$ & 157.500 & 159.098 \\
\hline Net longwave radiation $\left(\mathrm{W} \mathrm{m}^{-2}\right)$ & $66^{\mathrm{b}}, 49.4^{1}$ & 59.100 & 56.602 \\
\hline Latent heat flux $\left(\mathrm{W} \mathrm{m}^{-2}\right)$ & $84.948^{\mathrm{c}}$ & 76.268 & 82.197 \\
\hline Sensible heat flux $\left(\mathrm{W} \mathrm{m}^{-2}\right)$ & $15.795^{\mathrm{d}}$ & 21.124 & 19.786 \\
\hline \multicolumn{4}{|l|}{ Other variables } \\
\hline \multicolumn{4}{|l|}{ Cloud fraction $(\%)$} \\
\hline Total & $62.5^{\mathrm{f}}, 66.715^{\mathrm{e}}$ & 59.982 & 62.151 \\
\hline High & $13.02^{\mathrm{e}}$ & 37.83 & 36.48 \\
\hline Medium & $20.05^{\mathrm{e}}$ & 21.42 & 20.99 \\
\hline Low & $28.03^{\mathrm{e}}, 43.8^{\mathrm{k}}$ & 37.59 & 42.07 \\
\hline Longwave cloud forcing $\left(\mathrm{W} \mathrm{m}^{-2}\right)$ & $30.355^{\mathrm{a}}$ & 30.164 & 29.531 \\
\hline Shortwave cloud forcing $\left(\mathrm{W} \mathrm{m}^{-2}\right)$ & $-54.163^{\mathrm{a}}$ & -55.146 & -54.648 \\
\hline Total cloud Liquid water path $\left(\mathrm{g} \mathrm{m}^{-2}\right)$ & $122.35^{\mathrm{g}}$ & 139.63 & 128.36 \\
\hline Precipitable water (mm) & $24.575^{\mathrm{h}}$ & 23.761 & 24.321 \\
\hline Precipitation (mm/day) & $2.69^{\mathrm{i}}, 2.61^{\mathrm{j}}$ & 2.613 & 2.819 \\
\hline
\end{tabular}

In the left second, third, and forth rows, numbers in the bracket represent the observations and the simulations

a ERBE (Harrison et al. 1990; Kiehl and Trenberth 1997)

b Kiehl and Trenberth (1997)

${ }^{c}$ ECMWF (Kållberg et al. 2004)

${ }^{d}$ NCEP (Kistler et al. 2001)

e ISCCP (visible/infrared cloud amount; Rossow and Schiffer 1999)

${ }^{\mathrm{f}}$ ISCCP (Rossow and Zhang 1995)

g Moderate resolution imaging spectroradiometer (MODIS; King et al. 2003)

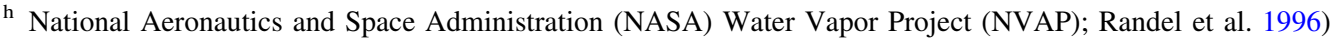

i CMAP precipitation (Xie and Arkin 1996)

j GPCP (Adler et al. 2003)

${ }^{\mathrm{k}}$ Warren et al. (1988)

${ }^{1}$ ISCCP FD (Zhang et al. 2004b)

$102.0 \mathrm{~W} \mathrm{~m}^{-2}$. The sum of the latent heat and sensible heat fluxes from the model is also nearly equal to that from the ERA-40 reanalysis products, although the latent heat flux at the surface simulated by BCC_AGCM2.0.1 $\left(76.8 \mathrm{~W} \mathrm{~m}^{-2}\right)$ is $8.0 \mathrm{~W} \mathrm{~m}^{-2}$ less than the ERA-40 data.

As shown in Table 1, the integrated precipitable water within the whole model atmosphere is underestimated (about $0.8 \mathrm{~mm}$ ) with respect to the NVAP data, and the global annual mean precipitation from the model is less than the CMAP precipitation climatology although it is in good agreement with the GPCP data. If we contrast BCC_AGCM2.0.1 to CAM3 simulations, there is an improvement in precipitation from BCC_AGCM2.0.1, which is attributed to the modification in the schemes for cumulus convection and the turbulent fluxes at the ocean surface.

Taylor diagrams (Taylor 2001) can give an overview of the statistical comparison of global fields from the model with observations and are useful for comparing the performance of different models. The similarity between two patterns is quantified in terms of their correlation and the amplitude of their variations (represented by their standard deviations). Figure 4 presents the Taylor diagrams to summarize the relative skill for the global distributions of annual mean climatologies from BCC_AGCM2.0.1 and CAM3 with corresponding observations and ERA-40 

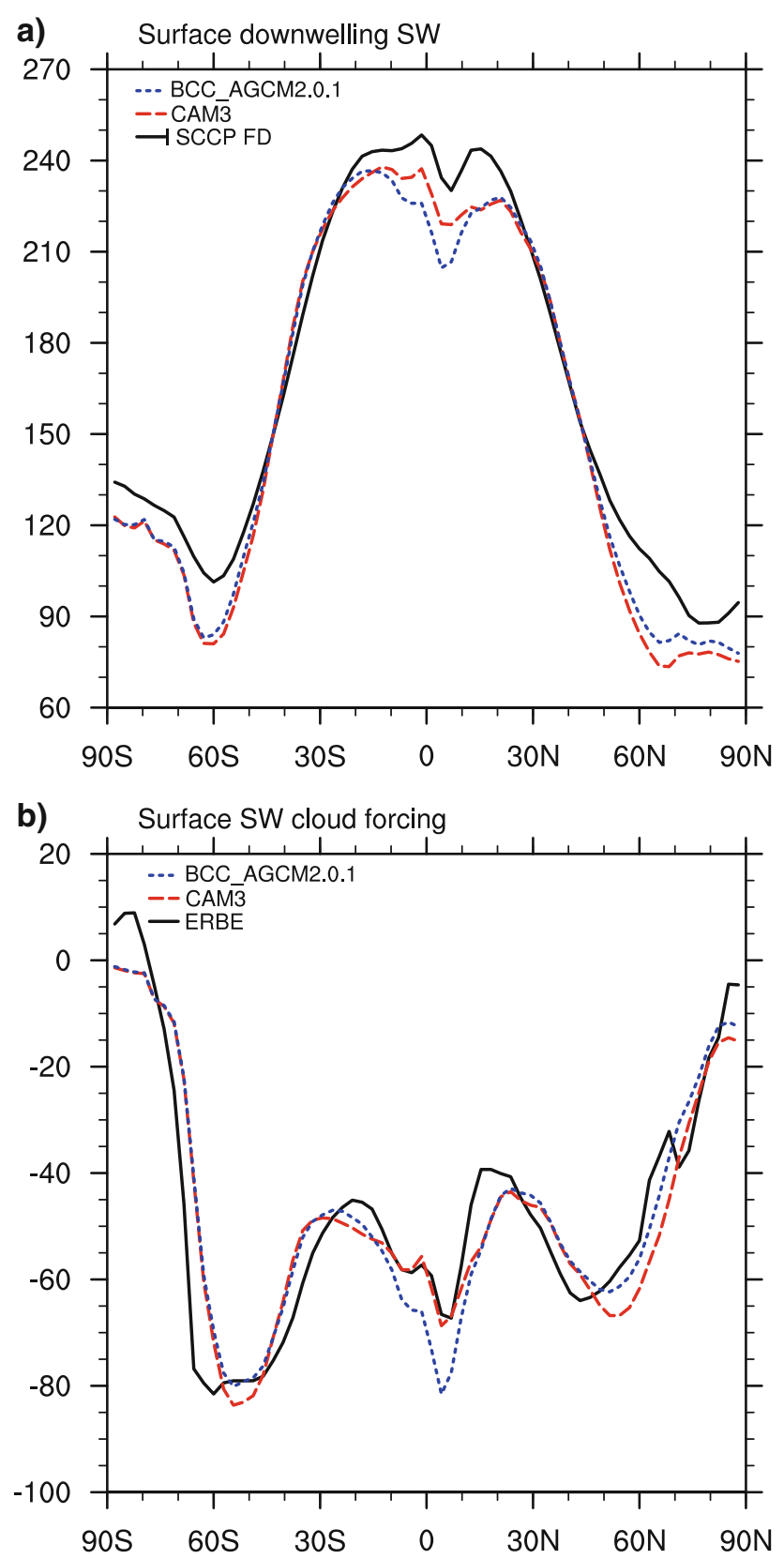

Fig. 3 Zonally averaged annual mean of a the surface downwelling solar radiation flux $\left(\mathrm{W} \mathrm{m}^{-2}\right)$ and $\mathbf{b}$ surface shortwave cloud forcing $\left(\mathrm{W} \mathrm{m}^{-2}\right)$ for the BCC_AGCM2.0.1, CAM3, and the ERBE and ISCCP FD data

reanalysis. A unique letter is assigned for different variables and the position of each letter appearing on the plot quantifies how closely that model's simulated pattern matches observations. The distance from the origin is the standard deviation of the field normalized by the standard deviation of the observationally based climatology. If the standard deviation of the model is the same as that of the climatology, then the radius is unity. The correlation between the model and the climatology is the cosine of the polar angle. If the correlation between the model and the climatology is unity, then the point will lie on the horizontal axis. Simulated patterns that agree well with observations lie close to the point marked "OBS" on the horizontal axis. In that case the simulations have relatively high correlation with observations and low root mean square (RMS) errors. Further, points lying on the dashed arc crossing "OBS" have the correct standard deviation, which indicates that the pattern variations are of the right amplitude.

As shown in Fig. 4, different variables can be roughly separated into three groups. The first group includes the temperature at $500 \mathrm{hPa}$ (t500 in Fig. 4a), the geopotential heights at 200 and $500 \mathrm{hPa}(\mathrm{z} 200$ and z500 in Fig. 4a), the outgoing longwave radiation and absorbed shortwave radiation at the top of the atmosphere, and the net shortwave radiation and latent heat flux at the surface (Fig. 4d). Simulated variation of such variables generally agrees well with observations. They have high correlations $(>0.90)$ with observations and the standard deviations are close to the observed ones (ranging from 0.75 to 1.25 times the observations). The locations for most variables in BCC_AGCM2.0.1 are much closer to the "OBS" and the amplitudes of the normalized standard deviations in BCC_AGCM2.0.1 are much closer to "1" than those in CAM3. The second group of variables such as the temperature at $850 \mathrm{hPa}$, the geopotential height at $850 \mathrm{hPa}$, the precipitation, the SLP, the longwave and shortwave cloud forcing, the longwave radiation at the surface, and the sensible heat flux have correlation coefficients between 0.75 and 0.90 with observations and the standard deviations range between 0.50 and 1.50 times the observed. Most of the second-group variables in BCC_AGCM2.0.1 also perform better than those in CAM3. The third group includes the temperature at $200 \mathrm{hPa}$, the relative humidity at $850 \mathrm{hPa}$, the high-, middle-, and low-cloud and total cloud amounts. Their simulations both in BCC_AGCM2.0.1 and in CAM3 have poor performance. Their pattern correlation coefficients are less than 0.75 and have large spatial variability (within $1 \mathrm{SD}$ compared to the observed values). The simulation for the variables of this group is in general less satisfactory in BCC_AGCM2.0.1 than in CAM3. An exception is the temperature at $200 \mathrm{hPa}$ with an evident improvements in BCC_AGCM2.0.1 (Fig. 4b), certainly due to the use of reference atmosphere included in the BCC_AGCM2.0.1 dynamical core. The poor performances of temperature at $200 \mathrm{hPa}$ and relative humidity at $850 \mathrm{hPa}$ are believed to be responsible for the discrepancy of cloud amounts (especially high clouds and low clouds).

The Taylor diagrams do not reveal any information about the vertical or horizontal distribution of errors in the models. These aspects are examined in the following sections. 
a)

Annual

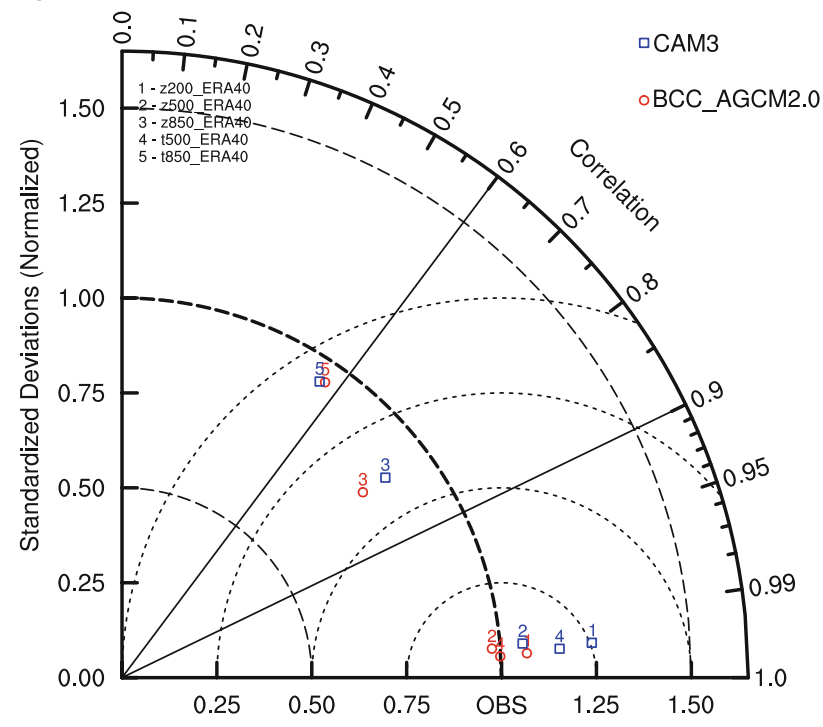

b)

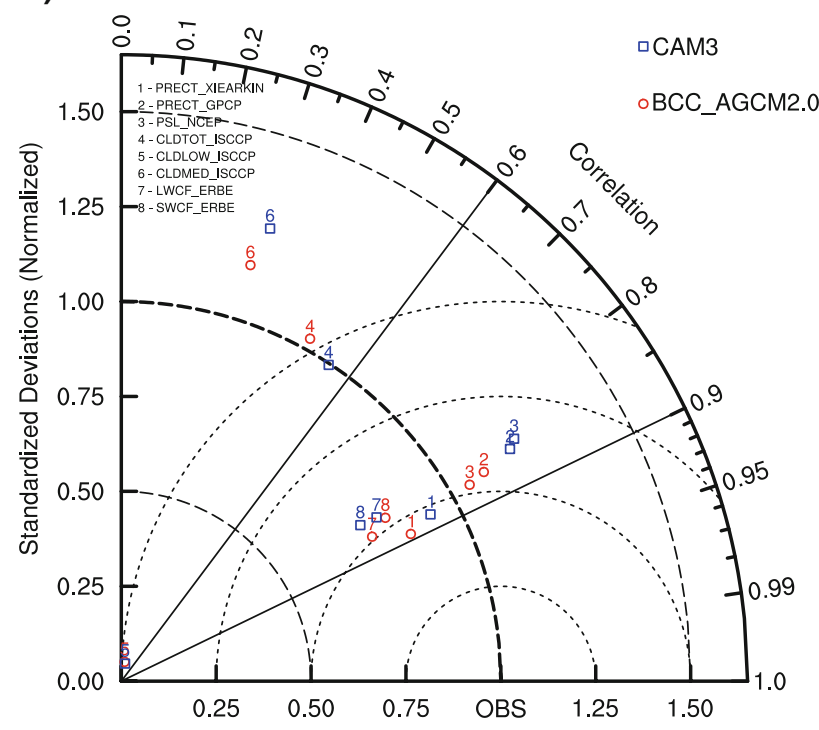

Fig. 4 Taylor diagrams summarize the comparison of BCC_AGCM2.0.1 with CAM3. The blue circles and red circles show the results from the BCC_AGCM2.0.1 and from the CAM3 compared with observations, respectively. Note: z200_ERA40, for example, shows the 200-hPa geopotential height simulation compared with the ERA-40 data. $z$ represents geopotential height, $t$ temperature, $q$ specific humidity, $r h$ relative humidity, PRECT precipitation, PSL pressure at mean sea level, CLDTOT total cloud, CLDLOW low

\subsubsection{Geographical distribution of precipitation}

The zonal-mean seasonal and annual precipitation rates from BCC_AGCM2.0.1 and Xie-Arkin's climatology are shown in Fig. 5. The main feature of the simulated precipitation is well consistent with the Xie-Arkin's climatology. As shown in Fig. 5b, c, the maximum precipitation is centred in the tropics and has seasonal c) Annual

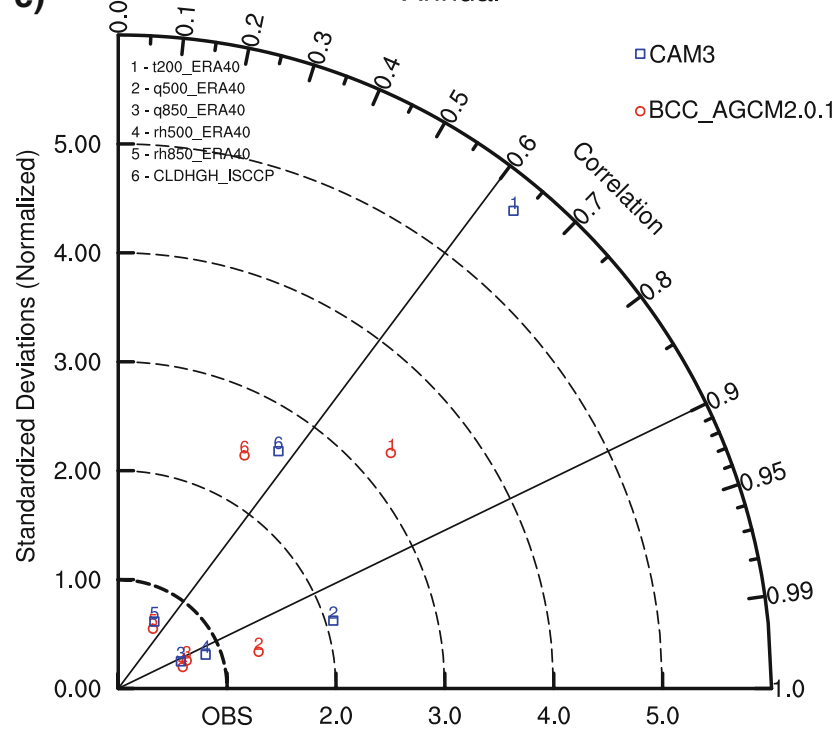

d)

Annual

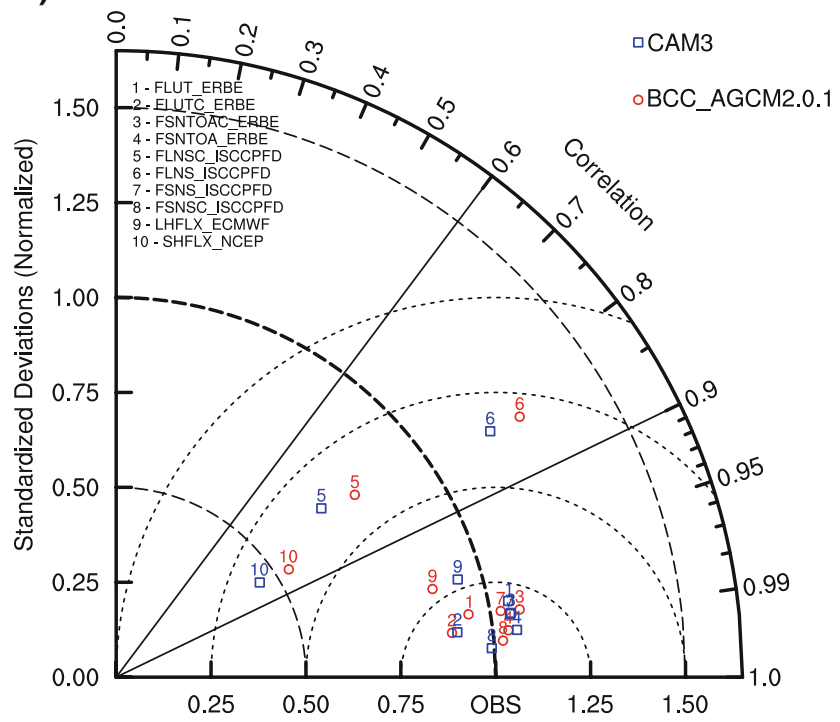

cloud, CLDMED mid-level cloud, CLDHGH high cloud, LWCF longwave cloud forcing, SWCF shortwave cloud forcing, FLUT upwelling longwave flux at top of model, FLUTC clearsky upwelling longwave flux at top of model, FSNTC clearsky net solar flux at top of model, FSNT net solar flux at top of model, FLNSC clearsky net longwave flux at surface, FLNS net longwave flux at surface, FSNS net solar flux at surface, FSNSC clearsky net solar flux at surface, LHFLX latent heat flux, SHFLX sensible heat flux

movement, i.e., it is located in the south in boreal winter (DJF) but in the north in boreal summer (JJA). This seasonal migration of maximum precipitation is closely associated with the seasonal migration of the intertropical convergence zone (ITCZ). The observed subtropical minimum and the second maximum precipitation over the middle-latitudes in Fig. $5 \mathrm{~b}, \mathrm{c}$ are also simulated by BCC_AGCM2.0.1 and in close agreement with the 

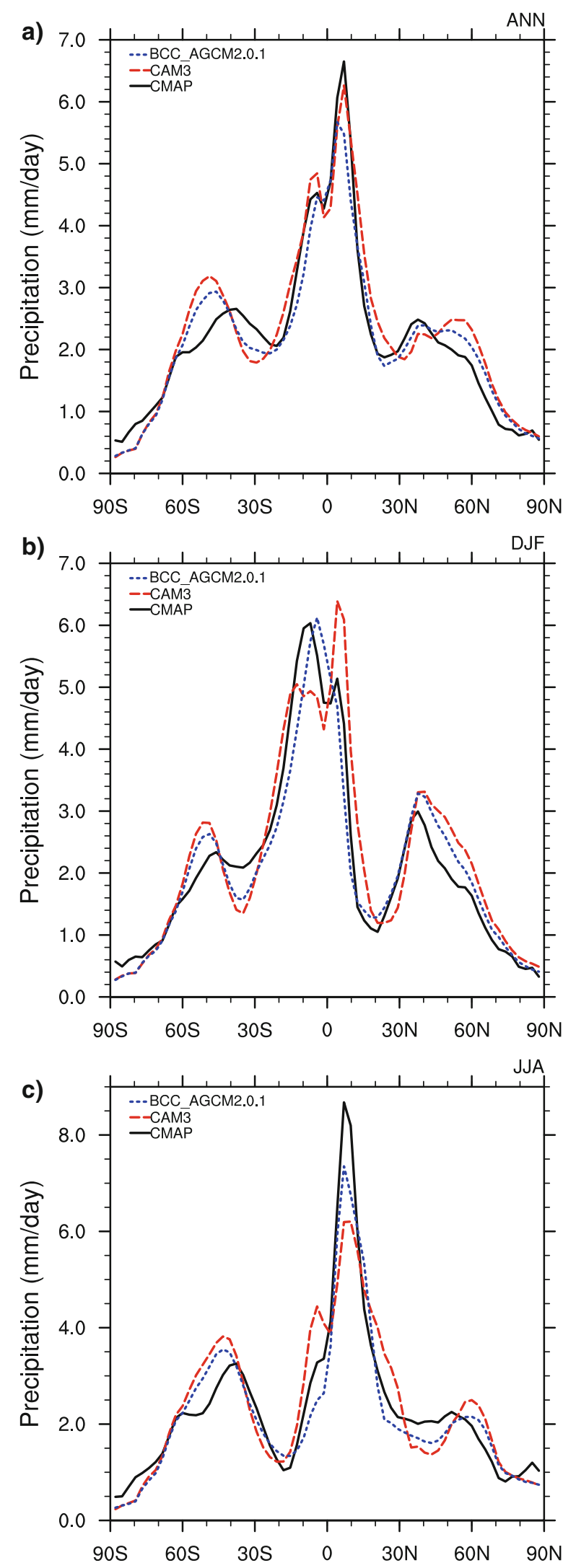

Fig. 5 Zonally averaged annual, DJF, and JJA precipitation rate in mm day $^{-1}$ for BCC_AGCM2.0.1, CAM3, and CMAP data locations of the observed precipitation. In contrast with the CAM3 simulation, large improvements in zonally mean precipitation from BCC_AGCM2.0.1 are the maximum in the tropics and minimum in the subtropics of both the hemispheres and the secondary maximum in the middlelatitudes.

There exist some obvious biases of precipitation between the BCC_AGCM2.0.1 simulation and the observation. For example, during DJF (Fig. 5b), the location of the simulated maximum peak south to the equator has an equatorward shift of about 3 degrees compared with the observation, and the second peak north to the equator from observation is not visible in the model simulation. During JJA (Fig. 5c), the simulated maximum rainfall is about $1.3 \mathrm{~mm} \mathrm{day}^{-1}$ less than the observation, although its geographic distribution in the model is close to that of the XieArkin's climatology. As for annual mean (in Fig. 5a), the precipitation rates between $40^{\circ} \mathrm{S}$ and $60^{\circ} \mathrm{S}$ and to the north of $40^{\circ} \mathrm{N}$ in the model are slightly higher than those from the observations, and slightly lower between $40^{\circ} \mathrm{S}$ and $40^{\circ} \mathrm{N}$.

The south-to-north seasonal migration of rain belt is much evident from the time-latitude section of the annual cycle of precipitation climatology as shown in Fig. 6. The broad northward shift of convection from boreal winter to boreal summer and southward from boreal summer to boreal winter are well captured by BCC_AGCM2.0.1. The double ITCZ in CAM3 (Fig. 6b) does not appear in BCC_AGCM2.0.1. The precipitation maximum from BCC_AGCM2.0.1 exhibits essentially a correct seasonal timing as that from the observation, except the location of the rain belt from December to April is shifted towards the equator and the strength of the rain belt from May to September is too strong, which is primarily attributed to the overly heavy precipitation over the Indian monsoon and the Southeast Asian monsoon areas.

Figure 7 shows the global geographical distributions of the mean DJF and JJA precipitation for BCC_AGCM2.0.1 and the Xie-Arkin's climatology. The overall patterns of the mean DJF and JJA precipitation from BCC_AGCM2.0.1 resemble the corresponding observations. As for the DJF mean, the large rainfall rate from CMAP data (Fig. 7c) over a zonal belt over the northern tropical Pacific zone near the equator, the western parts of the southern tropical Pacific, the southern tropical Indian Ocean, South Africa, and the South American continent are all well captured by BCC_AGCM2.0.1 (Fig. 7a). The secondary maxima of precipitation over mid-latitudes where fronts and their associated disturbances usually predominate are reasonably well reproduced. The low precipitation rates over the eastern parts of the subtropical oceans of both the hemispheres are also well simulated. For the JJA mean (Fig. 7d, f), large rainfall is mainly distrib- 

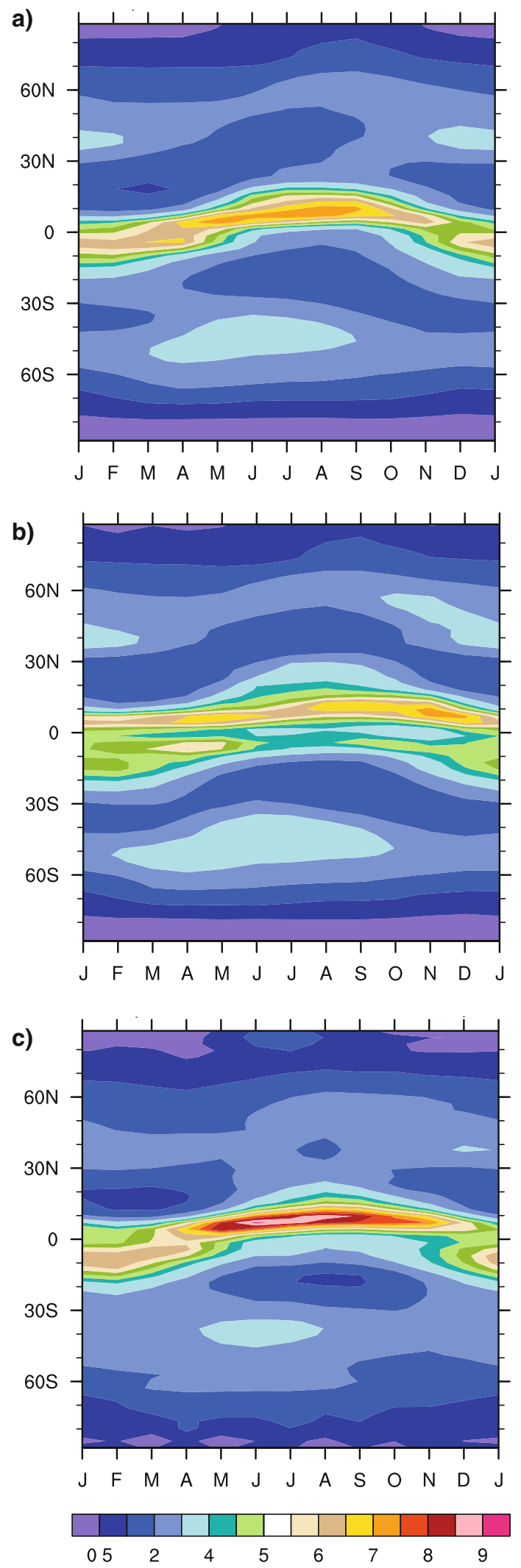

Fig. 6 The seasonal south-north march of zonally averaged precipitation $\left(\mathrm{mm} \mathrm{day}^{-1}\right.$ ) for BCC_AGCM2.0.1 (top), CAM3 (middle), and CMAP (bottom) uted along the equatorial Pacific and the Asian monsoon area. The observed patterns of precipitation over the Asian monsoon region with three maximum precipitation centers over the western coast of the Indian Peninsula, the Bay of Bengal, and the Philippines are reproduced by BCC_AGCM2.0.1.

With contrast to the CAM3 model, remarkable improvement in regional precipitation from BCC_AGCM2.0.1 are in the tropics of both the hemispheres especially for the DJF maxima in the South Pacific convergence zone (SPCZ) and in the southern tropical Indian ocean, the JJA maxima in the Bay of Bengal and in the western Pacific.

When comparing with the Xie-Arkin's climatology, regional biases of precipitation from BCC_AGCM2.0.1 can be observed. For example, the simulated mean DJF precipitation over the SPCZ is too strong and shifted too much westward in location. The rain belt in the tropical Indian Ocean is too close to the equator. The observed rain belt over southern China is too weak in the model. During JJA, the location of the precipitation maximum in the Bay of Bengal extends too westward and the maximum over the Indian peninsula is stronger than the observation and evidently expands out. Over China, the rain belt is shifted northward and there is less precipitation in the southeastern part of China in the simulation as compared with the observation.

\subsubsection{Vertical profiles of temperature and humidity}

Figure 8 shows the vertical profiles of the annual zonal average temperature from BCC_AGCM2.0.1 and the ERA40 reanalysis climatology and the difference between them. Overall, the model does a fairly good job in reproducing the analyzed thermal structure (Fig. 8a, b). Simulated tropospheric temperatures are within $1-3 \mathrm{~K}$ of the analyzed field for most of the domain equatorward of $50^{\circ} \mathrm{N}$ and $40^{\circ} \mathrm{S}$ (Fig. 8c). There is a notable cold bias in high-latitude midto upper-troposphere. The maximum cold bias relative to the ERA-40 reanalyses is below $-7 \mathrm{~K}$ at high latitudes of the Northern Hemisphere $(\mathrm{NH})$ and $-9 \mathrm{~K}$ at high latitudes of the Southern Hemisphere ( $\mathrm{SH})$. It is possibly associated with incorrect positioning of the tropopause. As shown in Fig. 8c, there exits a large cold bias near the tropical tropopause. The cold bias around the tropopause has hampered modeling the exchange of water vapor with the stratosphere (Hack et al. 2006). It may also influence the energy exchange between the troposphere and the stratosphere. The temperature in the lower stratosphere in BCC_AGCM2.0.1 is warmer than that of the ERA-40 reanalysis.

The cold tropospheric bias is also evident in CAM3 (Fig. 8d). With contrast to the CAM3 simulation, the cold biases in BCC_AGCM2.0.1 get slightly weaker to the 
a)

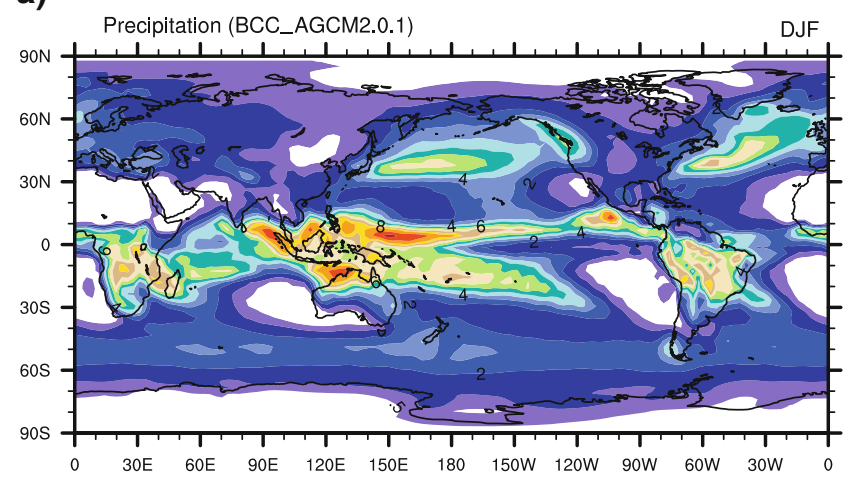

b) Precipitatıon (CAM3)

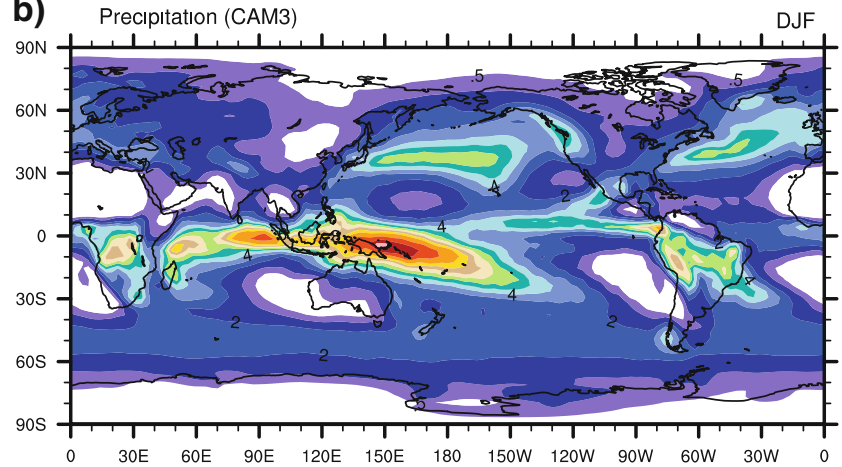

c) Precipitation (CMAP)

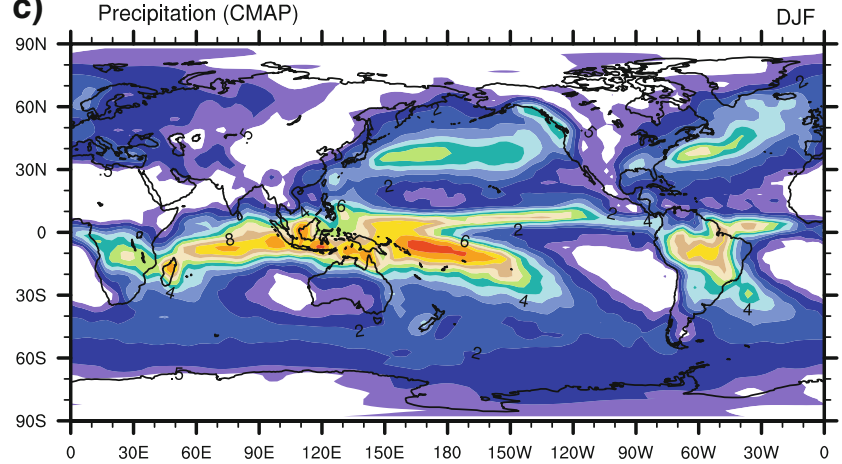

d)

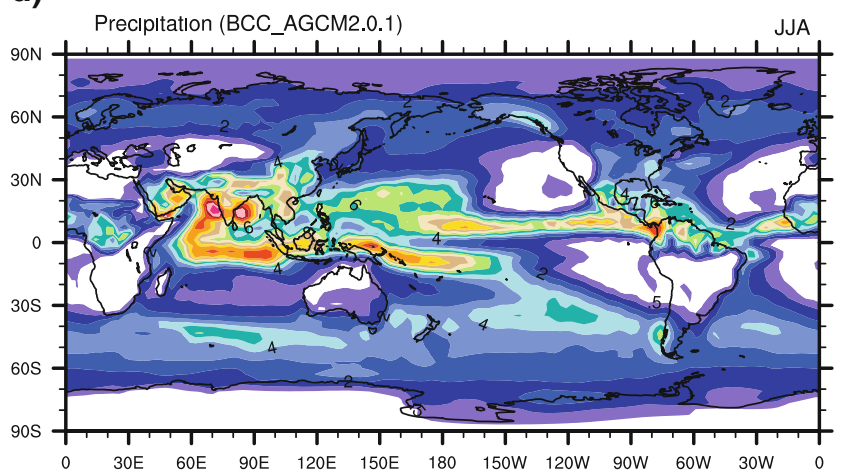

e) Precipitation (CAM3)

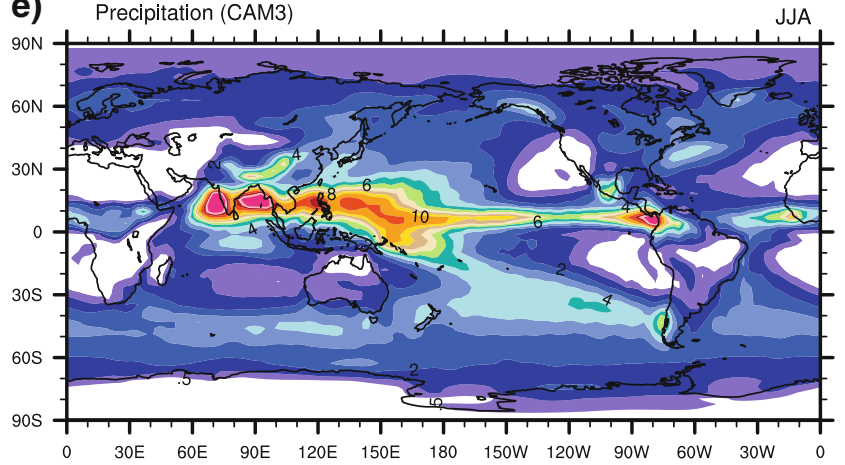

f) Precipitation (CMAP)

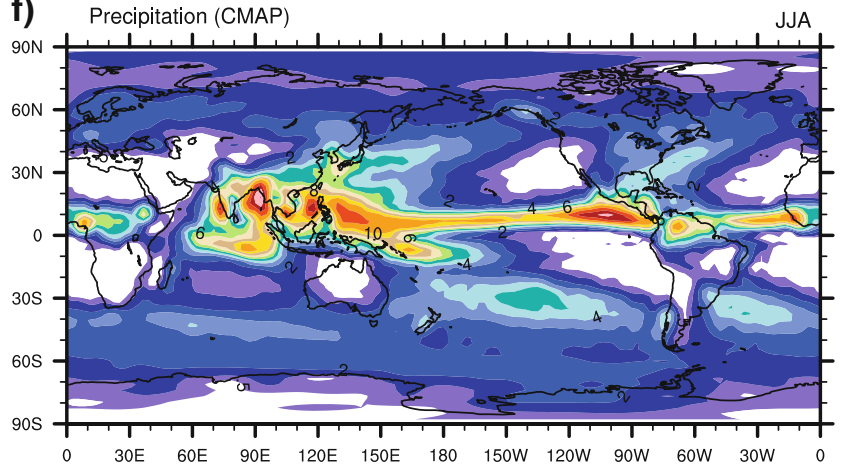

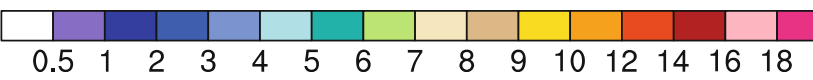

Fig. 7 Mean DJF (left) and JJA (right) precipitation $\left(\mathrm{mm} \mathrm{day}^{-1}\right.$ ) from BCC_AGCM2.0.1 (top), CAM3 (middle) and the CMAP (bottom)

polarward of $40^{\circ} \mathrm{N}$ and $40^{\circ} \mathrm{S}$, but are enlarged in the lower latitudes. The improvements in middle and high latitudes are possibly attributed to BCC_AGCM2.0.1 dynamics particularity from the CAM3 dynamic core (Wu et al. 2008). The poor performance in low latitudes may be associated with inconsistency between the modified cumulus convective parameterization in BCC_AGCM2.0.1 and the parameterizations for cloud and radiation that are unchanged from CAM3.

Besides the impact of the temperature on the cloud formation, the water vapor is another important factor. Although global observational data on the vertical distribution of water vapor in the atmosphere are still nonexistent and atmospheric analysis products contain large uncertainties in the moisture field (e.g., Trenberth and Guillemot 1995), the ERA-40 reanalysis data provides us with the best available estimates (Hack et al. 2006). As shown in Fig. 9a, b, BCC_AGCM2.0.1 captures the main patterns of the specific humidity from the ERA-40 reanalysis, such as the annual mean maximum over the southern tropical latitudes. With contrast to the CAM3, the large drier biases between $30^{\circ} \mathrm{S}$ and $30^{\circ} \mathrm{N}$ in the lower troposphere (below about $600 \mathrm{hPa}$ ) and wetter biases above in BCC_AGCM2.0.1 are smaller.

As shown in Fig. 9c, d, the model biases in specific humidity are small in magnitude. However, the relative 
Fig. 8 The pressure-latitude sectors of annual mean temperature from BCC_AGCM2.0.1 (a) and the ERA-40 data (b), the biases of BCC_AGCM2.0.1 (c) and CAM3 simulations (d) with contrast to the ERA-40. Intervals are $5 \mathrm{~K}$ in $\mathbf{a}$ and $\mathbf{b}$ and $1.5 \mathrm{~K}$ in $\mathbf{c}$ and $\mathbf{d}$
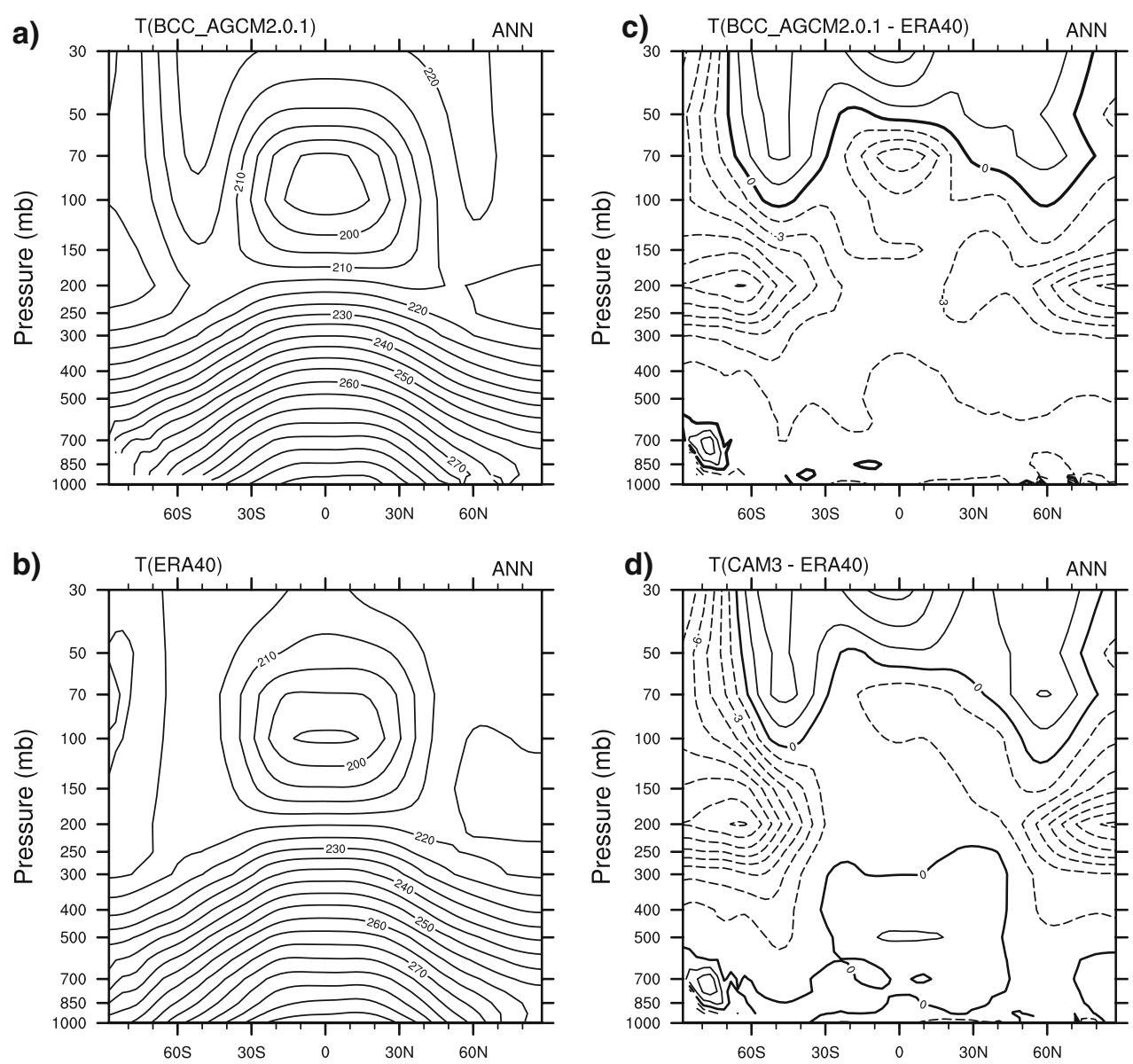

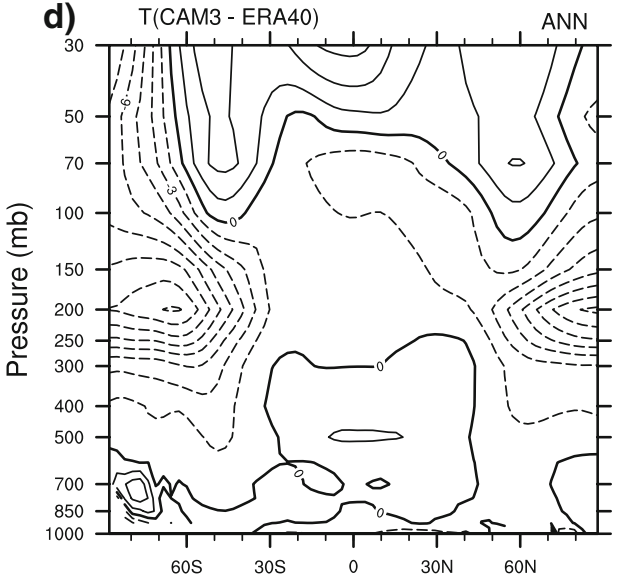

humidity biases may be quite large. The cold biases in midto upper-troposphere in BCC_AGCM2.0.1 can reduce the saturated specific humidity, and thus cause a large increase of the relative humidity. As shown in Fig. 9g, h, the relative humidity above $400 \mathrm{hPa}$ is evidently larger than the ERA-40 reanalysis data.

Large relative humidity in the model may have caused the overestimate of the layered cloud $\left(C_{\mathrm{c}}\right)$. In BCC_AGCM2.0.1 it is assumed that cloud forms when the relative humidity $\mathrm{RH}$ exceeds a threshold value $\mathrm{RH}_{\text {min }}$ which varies according to pressure in the model and $C_{\mathrm{c}}$ is diagnosed using the formula

$C_{\mathrm{c}}=\left(\frac{\mathrm{RH}-\mathrm{RH}_{\min }}{1-\mathrm{RH}_{\min }}\right)^{2}$.

The vertical distribution of the relative humidity bias as shown in Fig. 9g must result in the overestimate of highcloud amount over the globe (Fig. 10a) and even the overestimate of the low cloud at high latitudes (Fig. 10c) where the cloud amount is dominated by the layered cloud. Lower temperature in upper tropospheric lower latitudes in BCC_AGCM2.0.1 than that in CAM3 (Fig. 8b, d) cause a little more high cloud between $30^{\circ} \mathrm{N}$ and $30^{\circ} \mathrm{S}$ in BCC_AGCM2.0.1 than that in CAM3 (Fig. 10a).

\subsubsection{The geopotential height}

The pattern of the 500-mb geopotential height field (Fig. 11) is a good representative of the mid-tropospheric circulation. During DJF, BCC_AGCM2.0.1 captures two major troughs off the east coasts of the Eurasian continent and North American continent, two major ridges over the western coast of North America and the eastern Atlantic, and a band of high geopotential height over the tropics and subtropical regions (Fig. 11a, b). During JJA, BCC_AGCM2.0.1 successfully reproduces the observed large-scale zonal symmetries of $500-\mathrm{hPa}$ geopotential height and the northern subtropical high belt from the eastern Pacific eastward to western Asia (Fig. 11e, f).

There exist systematic zonally distributed differences of 500-hPa geopotential height from BCC_AGCM2.0.1 with respect to the ERA-40 reanalysis data (Fig. $11 \mathrm{c}, \mathrm{g}$ ). During DJF, the systematic errors are characterized by too low geopotential over the equatorward of $60^{\circ} \mathrm{S}$ and $60^{\circ} \mathrm{N}$ and too high geopotential over the polarward of $60^{\circ} \mathrm{S}$ with contrast to the ERA-40 data. This systematic error in the SH in DJF also occurs in JJA. But the biases in the NH in JJA are nearly opposite to those in DJF, i.e., higher 
Fig. 9 The pressure-latitude sectors of annual mean specific humidity (left panel) and relative humidity (right panel) from BCC_AGCM2.0.1, the ERA-40 data, and the biases of BCC_AGCM2.0.1 and CAM3 simulations with contrast to the ERA-40 data. Intervals are $1 \mathrm{~g} \mathrm{~kg}^{-1}$ in $\mathbf{a}$ and $\mathbf{b}, 0.3 \mathrm{~g} \mathrm{~kg}^{-1}$ in $\mathbf{c}$ and $\mathbf{d}$, and $5 \%$ in $\mathbf{e}-\mathbf{h}$
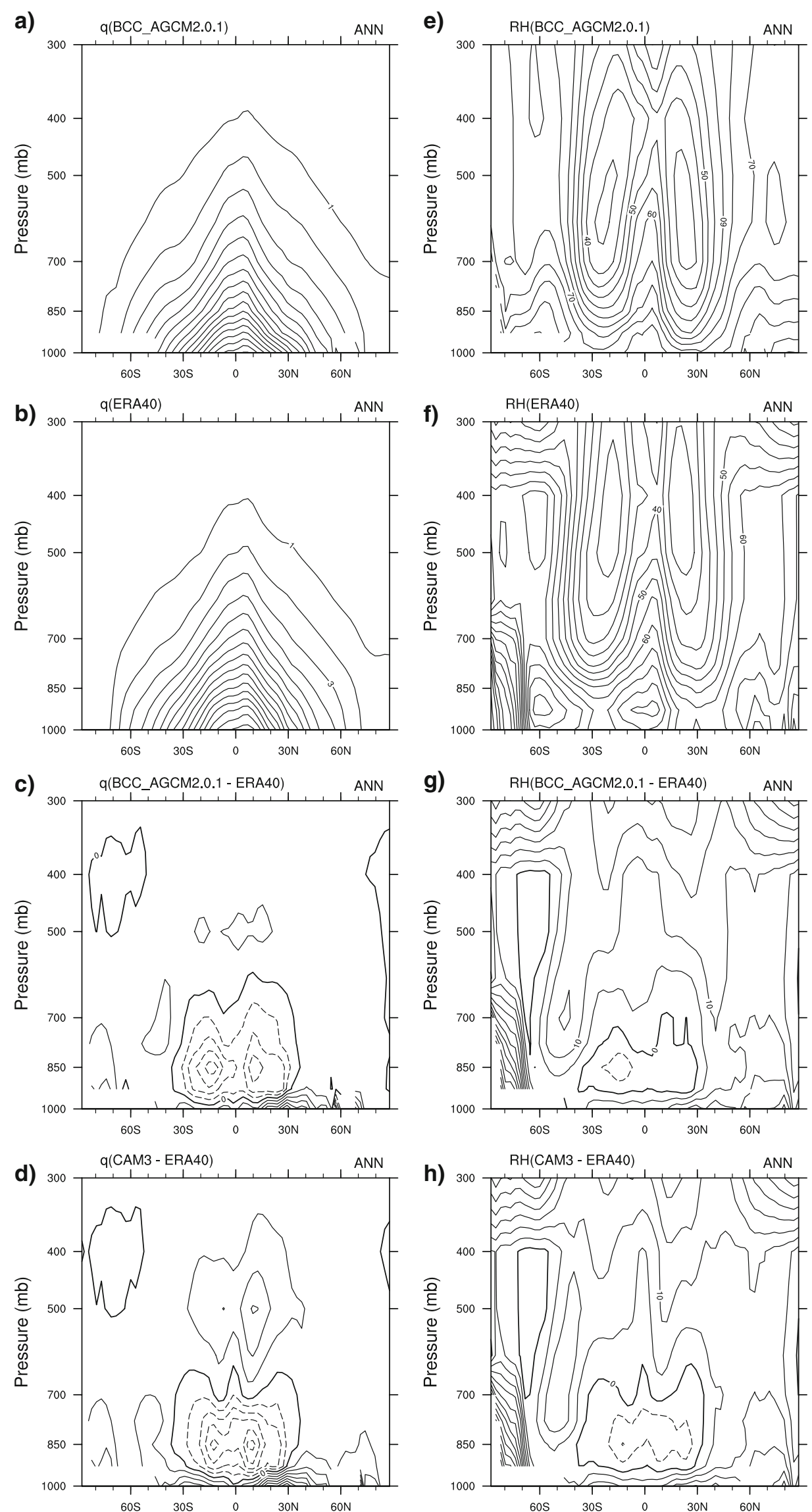

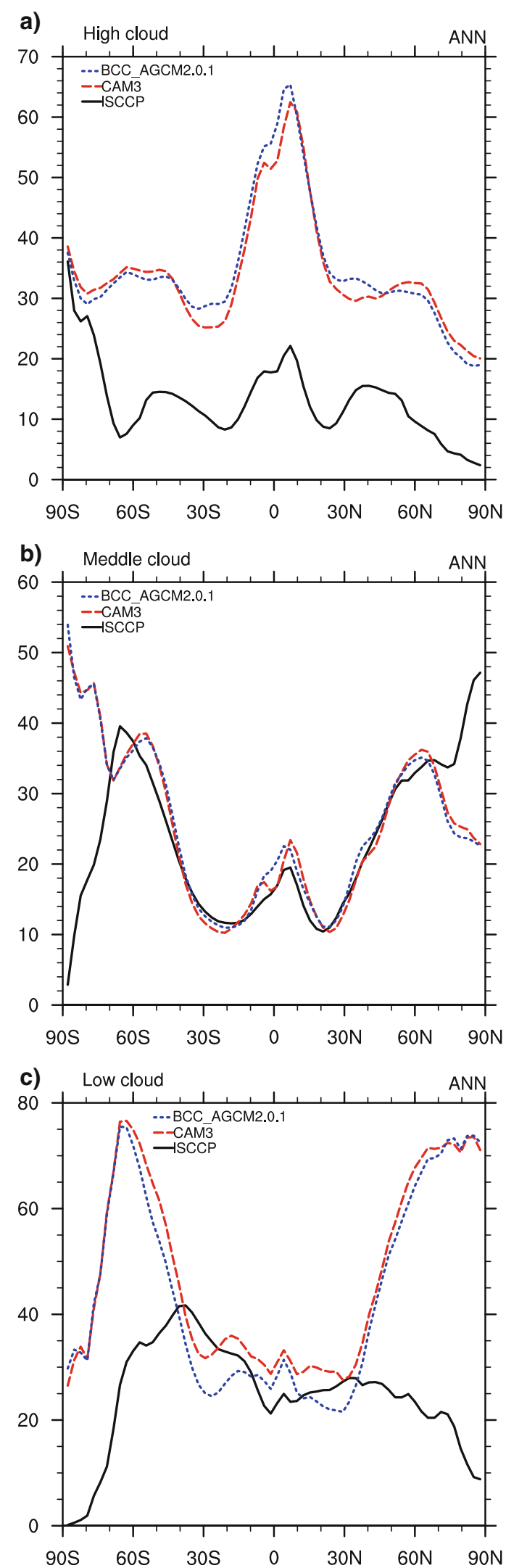

Fig. 10 Zonally averaged annual mean high-, middle-, and low-cloud amounts (\%) for the BCC_AGCM2.0.1, CAM3, and the ISCCP data geopotential over the equatorward of $50^{\circ} \mathrm{N}$ and lower geopotential over the polarward of $50^{\circ} \mathrm{N}$.

As shown in Fig. 11a, the ridge over the west coast of North America during DJF is slightly shifted westward, resulting in an error of 4 gpdm over the North Pacific and -8 gpdm over North America (in Fig. 11c) which are coincident to the positive SLP error over the north Pacific and the negative SLP error over North America (Fig. 12c), respectively. During JJA, a zone of positive bias of JJA 500-hPa height over the northern tropics (Fig. 11g) shows a remarkable difference between the BCC_AGCM2.0.1 simulation and the ERA-40 reanalysis data, which is also correspondent to high SLP error (Fig. 12g) in the same place from BCC_AGCM2.0.1. The details of the SLP biases are discussed in the following section.

With contrast to the CAM3 simulation, remarkable improvement for the DJF mean $500 \mathrm{hPa}$ geopotential height from BCC_AGCM2.0.1 is in the northern higher latitudes from Europe to the northern Pacific and that for the JJA mean almost in the whole northern hemisphere.

\subsubsection{Sea level pressure}

The SLP pattern is a useful indication of a GCM's ability to simulate the atmospheric circulation near the surface. SLP represents an integrated measure of a model's thermodynamic and dynamic representations. The global distributions of SLP from BCC_AGCM2.0.1 and the ERA-40 climatology averaged for DJF and JJA are shown in Fig. 12. The model well reproduces the main patterns of the observed SLP in winter and summer. Over the NH, the Aleutian and Icelandic low-pressure and Mongolia high-pressure systems during DJF (Fig. 12a), the subtropical high pressure over the Pacific and Atlantic during JJA (Fig. 12e) are all in good agreement with the observations (Fig. 12b, f), respectively. Over the $\mathrm{SH}$, a nearly continuous low-pressure zone close to the equator (i.e., the intertropical convergence zone ITCZ) and a belt of subtropical high pressure with the centers in each of the Pacific, Atlantic, and Indian oceans in both seasons (DJF and JJA) are captured by the model.

Significant regional biases, however, are noticeable in BCC_AGCM2.0.1. The SLP throughout the northern subtropics especially over the North Pacific is higher than the ERA-40 reanalysis data. There is an evident zone of lower SLP bias between $40^{\circ} \mathrm{S}$ and $60^{\circ} \mathrm{S}$. Large regional differences over areas of high topography (e.g., the Himalayas, Greenland, the Andes, and Antarctica), which are partly the results of extrapolation of atmospheric temperature from surface to sea level. As stated by Hurrell et al. (2006), large SLP differences over elevated regions is noisy and the magnitudes are not meaningful because of the sea level reduction problem. 

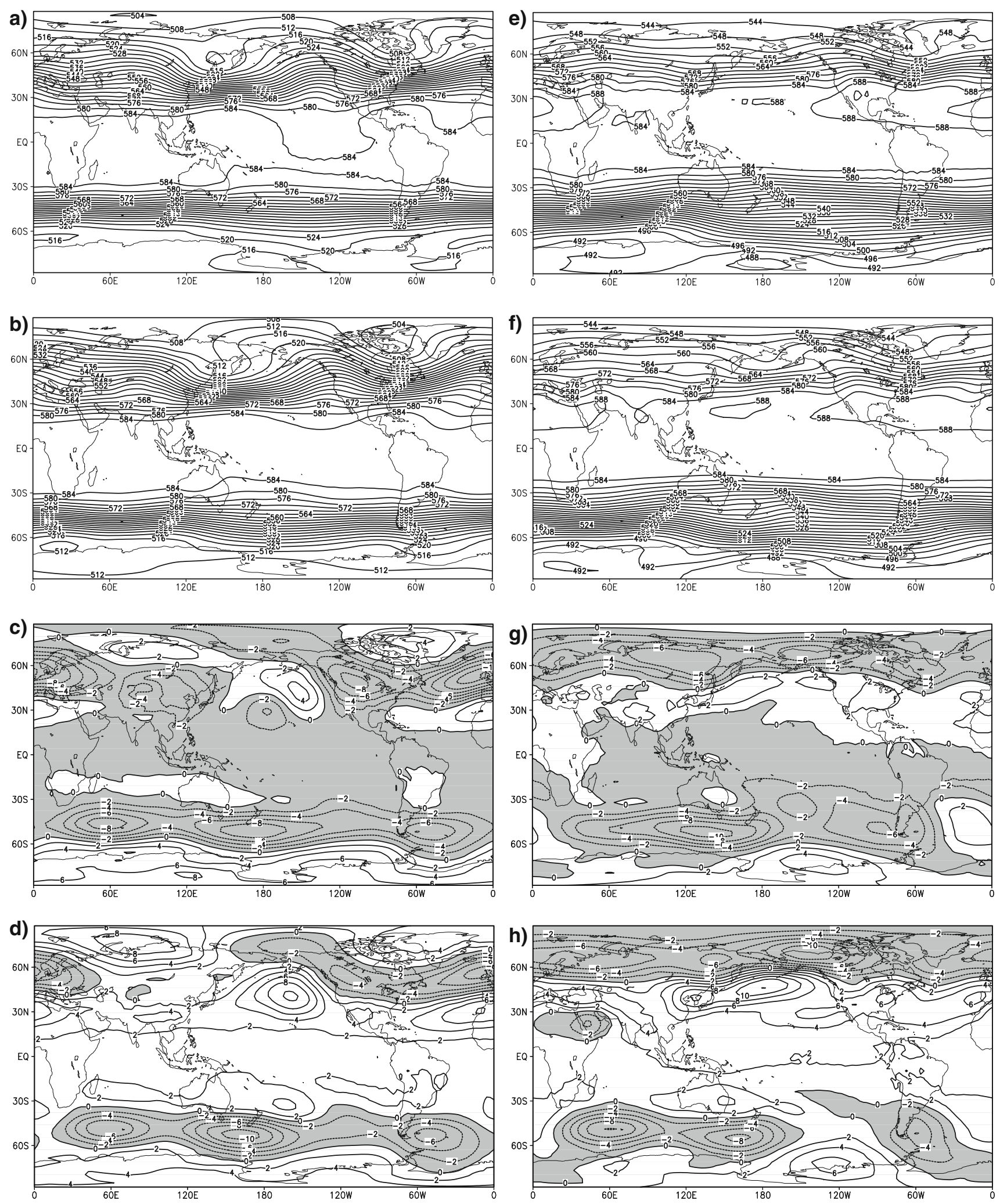

Fig. 11 Mean DJF (left) and JJA (right) 500-hPa geopotential height (gpdm) from BCC_AGCM2.0.1, the ERA-40, and the biases of BCC_AGCM2.0.1 and CAM3 simulation with contrast to ERA-40

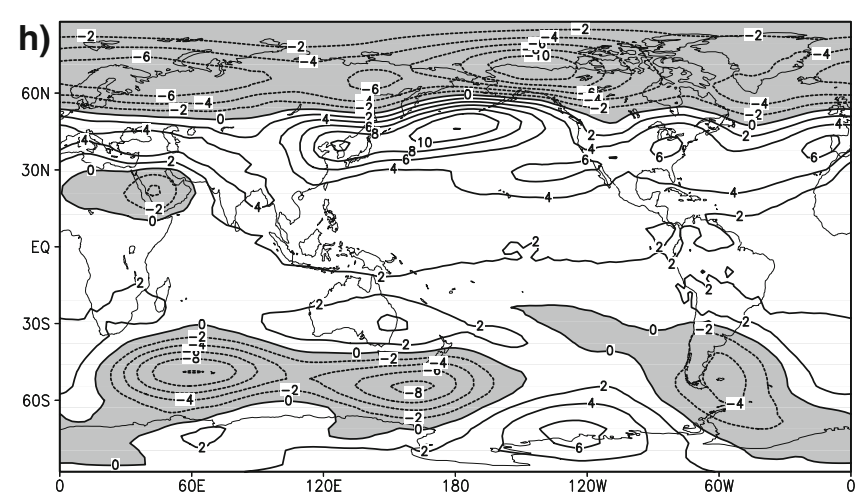

data. Intervals are $4 \mathrm{gpdm}$ in $\mathbf{a}, \mathbf{b}, \mathbf{e}$, and $\mathbf{f}$, and $2 \mathrm{gpdm}$ in $\mathbf{c}, \mathbf{d}, \mathbf{g}$ and h. Shaded areas in $\mathbf{c}, \mathbf{d}, \mathbf{g}$ and $\mathbf{h}$ indicate negative values there 

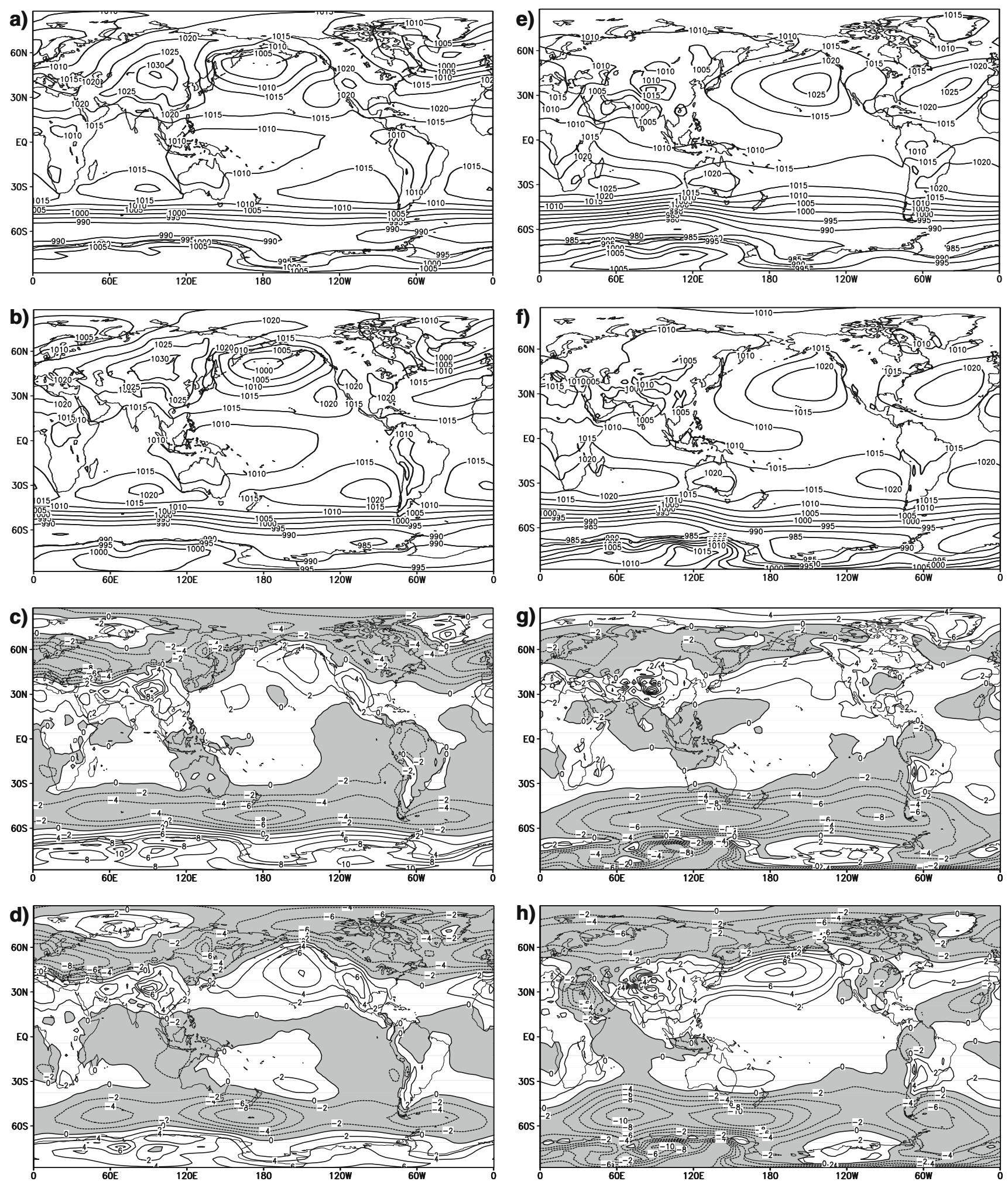

Fig. 12 The same as in Fig. 11, but for the SLP. Unit: mb. Intervals are $5 \mathrm{mb}$ in $\mathbf{a}, \mathbf{b}$, e, and $\mathbf{f}$ and $2 \mathrm{mb}$ in $\mathbf{c}, \mathbf{d}, \mathbf{g}$, and $\mathbf{h}$. Shaded areas indicate negative biases of simulation with contrast to the ERA-40 data

Although the SLP biases in BCC_AGCM2.0.1 (Fig. $12 \mathrm{c}, \mathrm{g}$ ) are generally similar in magnitude and position to those evident in CAM3 (Fig. 12d, h), but the biases in the northern hemisphere in BCC_AGCM2.0.1 are obvious weakened, not only for DJF mean but also for JJA mean. 
This improvement from BCC_AGCM2.0.1 is also evident in zonally averaged distribution. As shown in Fig. 13, the pressure in subtropics from CAM3 simulation is higher than the ERA-40 reanalysis, but in high latitudes lower than the observations. This bias in BCC_AGCM2.0.1 is reduced with comparison to that in CAM3. Although this improvement is not significant, we can still visually find it in Fig. 13.

\subsubsection{General circulation}

Zonal wind is one of the fundamental variables of the atmospheric circulation (Peixoto and Oort 1992) and thus needs to be checked in a climate simulation. Figure 14 shows the DJF and JJA zonal average differences of zonal winds between BCC_AGCM2.0.1 and the ERA-40 reanalysis climatology. Overall, the vertical structure of zonal wind is well simulated by the model. For example, the strongest westerlies more than $40 \mathrm{~m} \mathrm{~s}^{-1}$ near $200 \mathrm{hPa}$ over the middle-latitudes of both the hemispheres, the observed maximum near $30^{\circ} \mathrm{N}$ during DJF and near $30^{\circ} \mathrm{S}$ during JJA linked with the second westerly maximum in the upper-troposphere that continues into the stratosphere, and the stratospheric easterly jet over the tropics are simulated in close agreement with the observations. The simulated low-level easterlies are of nearly equal magnitude and location in each winter hemisphere.

The zonal wind biases from BCC_AGCM2.0.1 seem to have a somewhat systematic distribution. The latitudepressure pattern of zonal wind bias during DJF (Fig. 14c) is similar to that during JJA (Fig. 14g). Over the tropics, the simulated lower-stratospheric easterlies are stronger than those in the reanalysis and there is an easterly bias of -2 to $-4 \mathrm{~m} \mathrm{~s}^{-1}$ in the layer between $30 \mathrm{hPa}$ and $70 \mathrm{hPa}$. The tropical upper-tropospheric westerlies are also stronger than those in the reanalysis with biases of $8-10 \mathrm{~m} \mathrm{~s}^{-1}$ between 70 and $500 \mathrm{hPa}$ (Fig. 14c, g). Over the middlelatitudes, especially between $30^{\circ} \mathrm{S}$ and $50^{\circ} \mathrm{S}$ and between $30^{\circ} \mathrm{N}$ and $60^{\circ} \mathrm{N}$, westerly wind bias of $4-6 \mathrm{~m} \mathrm{~s}^{-1}$ occurs in almost the whole troposphere. This pattern of westerly biases off the equator is closely linked to the cold temperature biases in higher latitudes of both hemispheres.

When the BCC_AGCM2.0.1 simulations are compared to the CAM3 simulations, the zonal wind biases in the polarward of $30^{\circ} \mathrm{N}$ and $30^{\circ} \mathrm{S}$ with respect to the ERA 40 data are reduced not only for the DJF mean but also for the JJA mean. However, the tropospheric biases in the lower latitudes are obviously enlarged in BCC_AGCM2.0.1.

The 200-hPa wind is a representative variable of the higher tropospheric circulation. As shown in Fig. 15, during DJF, the strongest westerlies from the ERA-40 data occur over the NH during winter and reach more than $70 \mathrm{~m} \mathrm{~s}^{-1}$ off the Asian coast which spreads westward to
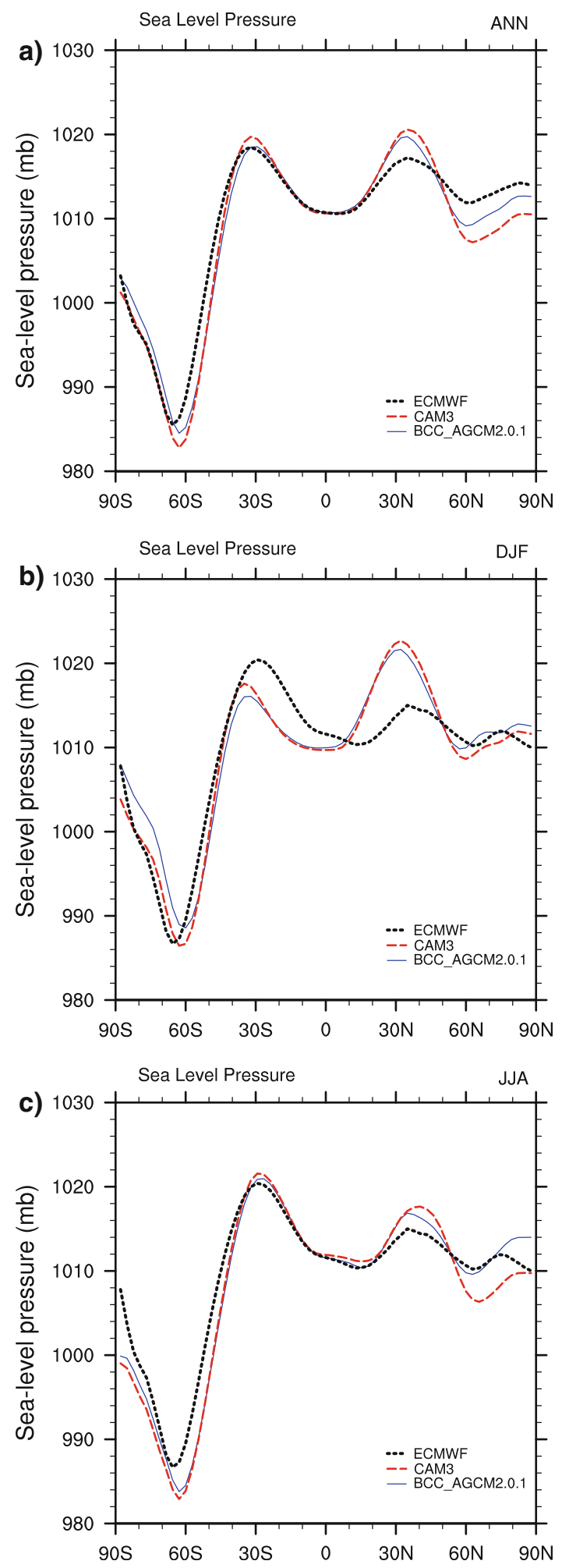

Fig. 13 The annual, DJF and JJA averaged zonal-mean SLP for the BCC_AGCM2.0.1, CAM3, and the ERA-40 reanalyses. Unit: mb

the African subtropical area and $40 \mathrm{~m} \mathrm{~s}^{-1}$ over the eastern United States and the western Atlantic. Over the SH the peak in the westerly is reached between $40^{\circ} \mathrm{S}$ and $50^{\circ} \mathrm{S}$ 
Fig. 14 Zonally averaged DJF and JJA zonal winds from the BCC_AGCM2.0.1 and ERA-40 reanalysis climatology, and the biases from the BCC_AGCM2.0.1 and CAM3 simulations with contrast to the ERA-40 data. Unit: $\mathrm{m} \mathrm{s}^{-1}$.

Intervals are $5 \mathrm{~m} \mathrm{~s}^{-1}$ in $\mathbf{a}, \mathbf{b}, \mathbf{e}$, and $\mathbf{f}$ and $2 \mathrm{~m} \mathrm{~s}^{-1}$ in $\mathbf{c}, \mathbf{d}, \mathbf{g}$, and h
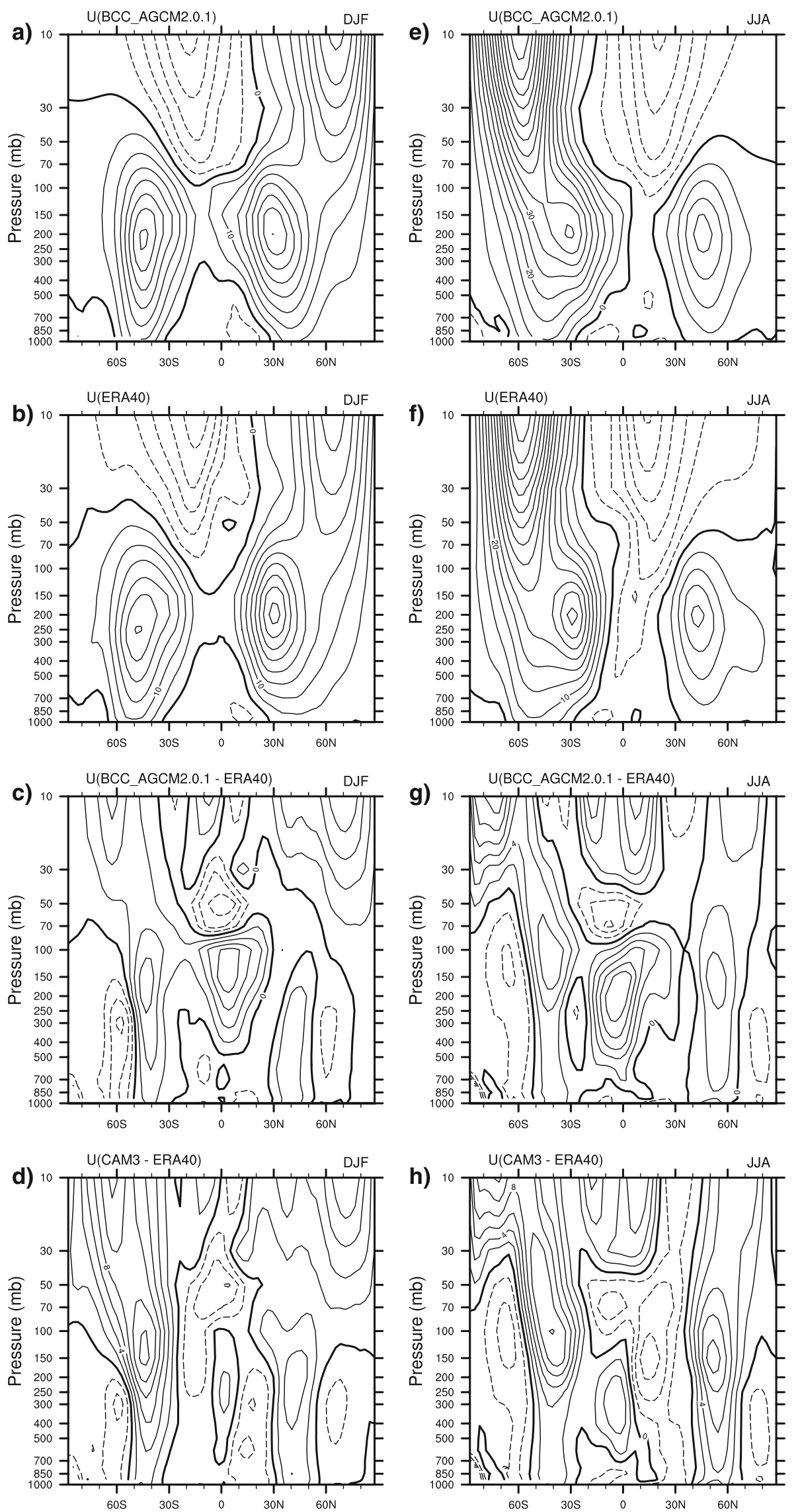

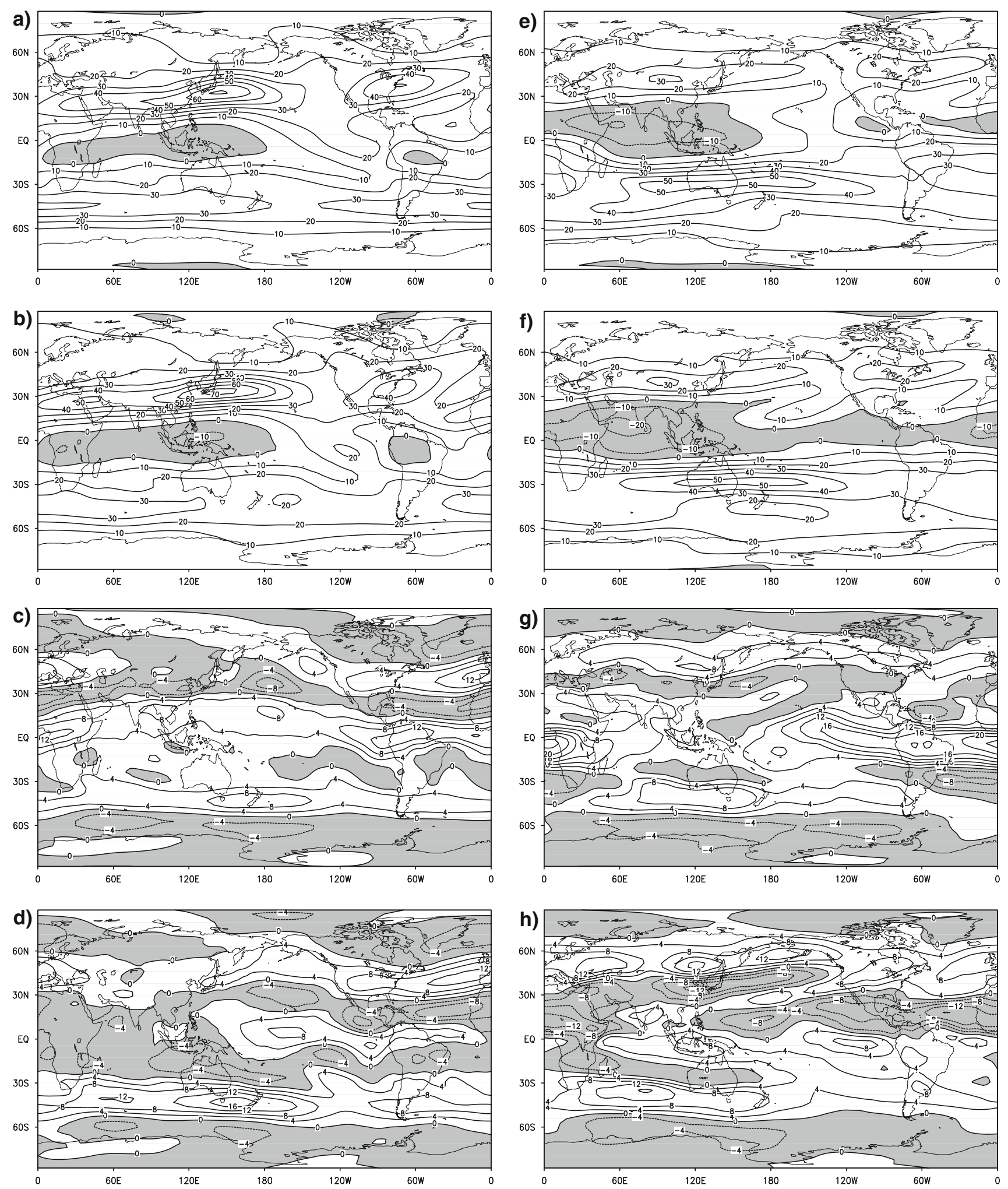

Fig. 15 The same as in Fig. 11, but for DJF and JJA mean $200 \mathrm{hPa}$ zonal wind. Unit: $\mathrm{m} \mathrm{s}^{-1}$. Intervals are $10 \mathrm{~m} \mathrm{~s}^{-1}$ in $\mathbf{a}, \mathbf{b}, \mathbf{e}$, and $\mathbf{f}$ and $4 \mathrm{~m} \mathrm{~s}^{-1}$ in $\mathbf{c}, \mathbf{d}, \mathbf{g}$, and $\mathbf{h}$

with maxima more than $30 \mathrm{~m} \mathrm{~s}^{-1}$ over the Atlantic and Indian Oceans. The strongest easterly is situated over the equatorial western Pacific to the equatorial Indian Ocean.
The whole wind fields such as the westerlies belt over the subtropics of both hemispheres and the easterlies belt in the tropics are seasonally moved northward and the southern 

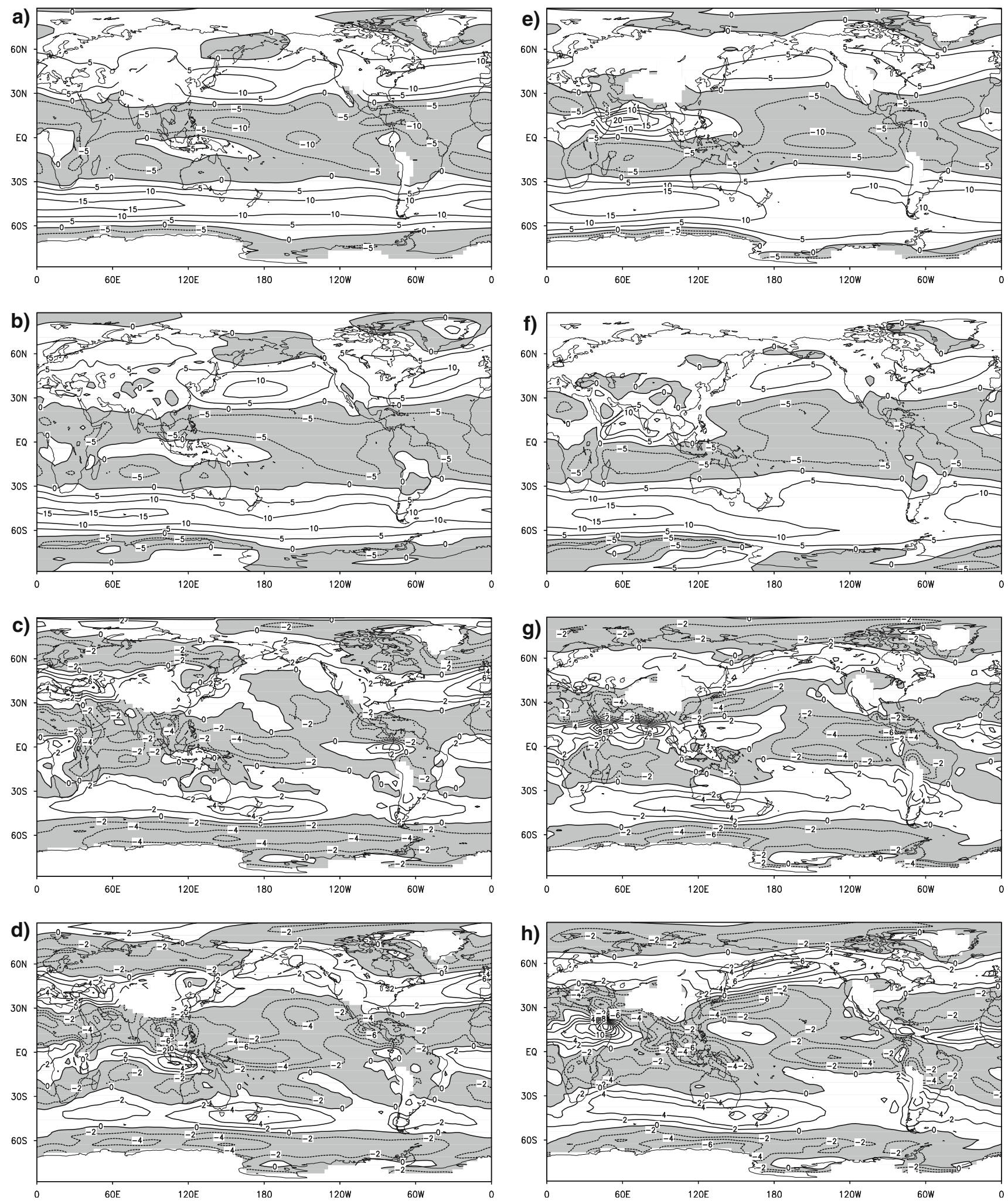

Fig. 16 The same as that in Fig. 11, but for 850-hPa zonal wind. Unit: $\mathrm{m} \mathrm{s}^{-1}$. Intervals are $5 \mathrm{~m} \mathrm{~s}^{-1}$ in $\mathbf{a}, \mathbf{b}, \mathbf{e}$, and $\mathbf{f}$ and $2 \mathrm{~m} \mathrm{~s}{ }^{-1}$ in $\mathbf{c}, \mathbf{d}, \mathbf{g}$, and $\mathbf{h}$

westerly becomes stronger and the northern westerly weaker in magnitude. The center of the easterlies located over southeastern Asia in DJF is moved to the Arabian Sea and the north part of the Indian Ocean. All of these mean features are well simulated by BCC_AGCM2.0.1 and in close agreement with the observations. 
The regional biases of the $200 \mathrm{hPa}$ zonal wind from BCC_AGCM2.0.1 compared with the ERA-40 reanalysis are shown in Fig. 15c, g. The locations of the biases are not geographically coincident to the climatological centers of westerlies or easterlies. In the $\mathrm{SH}$, the geographical pattern of zonal wind biases in DJF resembles to that in JJA. A striking feature of the 200-hPa zonal winds is a belt of westerly bias near $40^{\circ} \mathrm{S}$ with maxima of $8-12 \mathrm{~m} \mathrm{~s}^{-1}$ to the south of Australia and a belt of easterly biases near $60^{\circ} \mathrm{S}$ with values near -4 to $-8 \mathrm{~m} \mathrm{~s}^{-1}$. In the $\mathrm{NH}$, the large differences are situated in the subtropical zone. The largest biases over the globe are along the equator, they are featured as westerly biases of $200-\mathrm{hPa}$ zonal wind with maxima extending from the equatorial eastern Pacific to western Africa, through central America and the equatorial Atlantic.

When we contrast to the CAM3, the maxima or minima of simulation biases from BCC_AGCM2.0.1 are obviously weakened in the southern hemisphere for the DJF mean and in the northern hemisphere for the JJA mean.

Figure 16 shows the mean DJF and JJA 850-hPa zonal wind from BCC_AGCM2.0.1 and the ERA-40 reanalysis climatology. The major features of the observed wind speed are well simulated by the model. During DJF, the model captures the tropical easterlies and the subtropical westerlies over both the hemispheres and reproduces the maxima of westerlies off the eastern coasts of Asia and North America. From DJF to JJA, there is a remarkable seasonal change of $850 \mathrm{hPa}$ wind in both the model and observation. The strength of the northern subtropical westerlies evidently becomes weaker during JJA than that during DJF and the center of the westerlies over North Pacific is slightly shifted polarward and eastward in JJA. Apart from the good performance of the model for the large-scale features, the model also captures some important regional features. For example, based on the observation, $850-\mathrm{hPa}$ zonal wind over the Asian monsoon and African monsoon regions (about $0^{\circ}-140^{\circ} \mathrm{E}$ and $0^{\circ}-$ $25^{\circ} \mathrm{N}$ ) has a clear seasonal change, i.e., from easterlies in winter to westerlies in summer. This reversal of the mean DJF and JJA zonal wind is well reproduced by the model.

Some differences between the model and the ERA-40 reanalysis still need to be noted. During DJF, the simulated westerly biases are mainly in the area of subtropical westerly jet in both hemispheres, especially off the eastern coasts of Asia and America, southern Europe, and between $30^{\circ} \mathrm{S}$ and $50^{\circ} \mathrm{S}$, and the easterly biases in the eastern coast and western part of the tropical Pacific, the tropical Indian Ocean, western Africa, the northern Atlantic near $60^{\circ} \mathrm{N}$, and a band near $60^{\circ} \mathrm{S}$. The pattern of $850-\mathrm{hPa}$ zonal wind bias over the region polarward of $30^{\circ} \mathrm{S}$ in Fig. $16 \mathrm{c}$ is closely linked geostrophically to the biases of the seal level pressure in Fig. 12c in which there exist a negative SLP difference to the north and a positive difference to the south of $60^{\circ} \mathrm{S}$. During JJA, the pattern of wind biases in the $\mathrm{SH}$ is almost the same as that in DJF. In the $\mathrm{NH}$, the regional feature is remarkable (Fig. 16g). The $850-\mathrm{hPa}$ wind difference off the eastern coasts of Asia are changed from a westerly bias in DJF to an easterly bias in JJA and over South Asia from an easterly bias in DJF to a westerly bias in JJA. This pattern of model biases means that the strength of the Indian monsoon in the model is stronger than that in the observations but the simulated East Asian monsoon is weaker than the observations. Over the western part of the $\mathrm{NH}$, the pattern of zonal wind biases in JJA almost resembles to that in DJF. When compared with CAM3 (Fig. 16d, h), remarkable improvement in the $850 \mathrm{hPa}$ zonal wind simulation from BCC_AGCM2.0.1 (Fig. 16c, g) can be attributed to the reduction of the easterly wind biases in the tropical and subtropical Pacific ocean.

\section{Summary and conclusion}

The major features of the BCC_AGCM2.0.1 are described in this paper. The governing equations in BCC_AGCM2.0.1 are originated from the Eulerian dynamics in CAM3 but substantial changes concerning the diagnostic equations and their resolving technique in terms of the use of the reference atmospheric temperature and reference surface pressure have been implemented in BCC_AGCM2.0.1. Most of the physical processes used in CAM3 remain unchanged in BCC_AGCM2.0.1, while the parameterizations for the deep cumulus convection, dry adiabatic adjustment, latent heat and sensible heat fluxes over ocean surface, and snow cover fraction in CAM3 are replaced with new schemes in BCC_AGCM2.0.1.

The new cumulus convective scheme is tested in BCC_AGCM2.0.1 to have better performance than its original ZM95 (Zhang and McFarlane 1995) and RZM schemes (Zhang and Mu 2005a) in providing improved simulation of the tropical maximum and the subtropical minimum of precipitation. The new scheme to calculate the wind stress, sensible heat flux, and latent heat flux at the ocean surface is also validated using the EPIC2001 in situ observations and show a noticeable improvement than its original scheme in CAM3.

BCC_AGCM2.0.1 is forced with the 1949-2000 observed monthly varying sea surface temperatures and sea ice concentrations and five sample runs are made. The fivemember ensemble simulation is evaluated against coexisting observations, which reveals that most aspects of the model are significantly improved in comparison to CAM3. The global statistical property shows that the model climatology for the radiation budget at the top of the atmosphere and at the surface is in agreement with the observed one and/or the reanalysis products. Large bias is 
mainly found for cloud amount in the model, especially the high cloud and low cloud have relatively large errors.

The simulation skill of BCC_AGCM2.0.1 for the global distributions of the annual mean climatologies is compared with that of CAM3. The comparison shows that BCC_AGCM2.0.1 performs in general better than CAM3 for the present-day climate, which may be attributed to the combined effect of the improved dynamics and physical processes. As a whole, mid-tropospheric temperature, geopotential height, atmospheric circulation, and energy fluxes at the top of the atmosphere and at the surface are well simulated among the analyzed variables. The less satisfactory aspect of the model mainly includes the cloud amount and related variables such as the relative humidity.

The simulated zonal-mean and global distribution of seasonal precipitation, temperature and humidity, SLP, and general circulation by BCC_AGCM2.0.1 are compared with those from the ERA-40 climatology. The overall agreement is fairly good. However, large regional biases still exist. Significant errors include the precipitation in the tropical western Pacific and Asian monsoon regions, the mid- and high-latitude upper-tropospheric temperature and relative humidity, the mid-latitude geopotential height and SLP.

BCC_AGCM2.0.1 as described in this paper will serve as a reference state and a starting point for further developments envisaged in the BCC, including a new convection scheme with a different triggering closure, a prognostic cloud water scheme, and a new radiative transfer scheme. Results of these works will be reported separately in the future.

Acknowledgments We would like to thank two anonymous reviewers for their constructive comments and Dr. Zhiqiu Gao for provide EPIC2001 data. This work was partly supported by the National Basic Research Program "973” (Grant No. 2004CB418303) of the Chinese Ministry of Science and Technology and the Special Promotion Program for Meteorology (Grant GYHY200806006).

Open Access This article is distributed under the terms of the Creative Commons Attribution Noncommercial License which permits any noncommercial use, distribution, and reproduction in any medium, provided the original author(s) and source are credited.

\section{References}

Adler RF et al (2003) The version-2 global precipitation climatology project (GPCP) monthly precipitation analysis (1979-present). J Hydrometeorol 4:1147-1167. doi:10.1175/15257541(2003)004<1147:TVGPCP $>2.0 . \mathrm{CO} ; 2$

Bao J-W, Wilczak JM, Choi J-K, Kantha LH (2000) Numerical simulations of air-sea interaction under high wind conditions using a coupled model: a study of hurricane development. Mon Weather Rev 128:2190-2210. doi:10.1175/1520-0493(2000)128 $<2190$ :NSOASI $>2.0 . \mathrm{CO} ; 2$
Collins WD et al (2004) Description of the NCAR Community Atmosphere Model (CAM3). Technical report NCAR/TN464+STR, National Center for Atmospheric Research, Boulder, Colorado, $226 \mathrm{pp}$

Collins WD et al (2006) The formulation and atmospheric simulation of the Community Atmosphere Model version 3 (CAM3). J Clim 19:2144-2161. doi:10.1175/JCLI3760.1

Ding Y, Liu Y, Song Y, Li Q (2002) Research and experiments of the dynamical model system for short-term climate prediction. Clim Environ Res 7:236-246 (in Chinese)

Ding Y, Li Q, Li W, Luo Y, Zhang P, Zhang Z, Shi X, Liu Y, Wang L (2004) Advance in seasonal dynamical prediction operation in China. Acta Meteorol Sin 62:589-612 (in Chinese)

Dong M (2001) NCC atmospheric general circulation model—basic principle and user's guide. China Meteorological Press, Beijing, 152 pp (in Chinese)

Foster J et al (1996) Snow cover and snow mass intercomparisons of general circulation models and remotely sensed datasets. J Clim 9:409-426. doi:10.1175/1520-0442(1996)009<0409:SCASMI> 2.0.CO;2

Hack JM, Caron JM, Yeager SG, Oleson KW, Holland MM, Truesdale JE, Rasch PJ (2006) Simulation of the global hydrological cycle in the CCSM Community Atmosphere Model version3 (CAM3): mean features. J Clim 19:2199-2221. doi: 10.1175/JCLI3755.1

Harrison EF, Minnis P, Barkstrom BR, Ramanathan V, Cess RD, Gibson GG (1990) Seasonal variation of cloud radiative forcing derived from the earth radiation budget experiment. J Geophys Res 95:18687-18703. doi:10.1029/JD095iD11p18687

Hollingsworth A, Arpe K, Tiedtke M, Capaldo M, Savijärvi H (1980) The performance of a medium-range forecast model in winter-impact of physical parameterization. Mon Weather Rev 108:1736-1773. doi:10.1175/1520-0493(1980)108<1736: TPOAMR $>2.0 . \mathrm{CO} ; 2$

Hurrell JW, Hack JJ, Phillips AS, Caron J, Yin J (2006) The dynamical simulation of the Community Atmosphere Model version 3 (CAM3). J Clim 19:2162-2183. doi:10.1175/ JCLI3762.1

Jarraud M, Simmons AJ, Kanamitsu M (1985) Development of the high resolution model. ECMWF Tech. Memo. 107, Reading, UK, $61 \mathrm{pp}$

Jin X, Zhang X, Zhou T (1999) Fundamental framework and experiments of the third generation of IAP/LASG world ocean general circulation model. Adv Atmos Sci 16:197-215. doi: 10.1007/BF02973082

Kållberg P, Simmons A, Uppala S, Fuentes M (2004) The ERA-40 archive. Technical report ERA-40 project rep. 17, European Centre for Medium-Range Weather Forecasts, Reading, UK, 35 $\mathrm{pp}$

Kiehl JT, Trenberth KE (1997) Earth's annual global mean energy budget. Bull Am Meteorol Soc 78:197-208. doi:10.1175/15200477(1997)078<0197:EAGMEB > 2.0.CO;2

King MD et al (2003) Cloud and aerosol properties, precipitable water, and profiles of temperature and water vapor from MODIS. IEEE Trans Geosci Remote Sens 41:442-458

Kistler R et al (2001) The NCEP-NCAR 50-year reanalysis: monthly means CD-ROM and documentation. Bull Am Meteorol Soc 82:247-267. doi:10.1175/1520-0477(2001)082<0247:TNNYRM $>2.3 . \mathrm{CO} ; 2$

Kraus EB, Businger JA (1994) Atmosphere-ocean interaction. Oxford University Press, Oxford, $362 \mathrm{pp}$

Li W, Zhang P, Li Q, Wang L, Liu Y, Shi X, Zhang Z (2005) Research and operational application of dynamical climate model prediction system. J Appl Meteorol Sci 16(suppl):1-11 in Chinese 
Oleson KW et al (2004) Technical description of the community land model (CLM). Technical report NCAR/TN-461+STR, National Center for Atmospheric Research, Boulder, Colorado, $174 \mathrm{pp}$

Peixoto JP, Oort AH (1992) Physics of climate. American Institute of Physics, New York, 520 pp

Randel DL, Greenwald TJ, Vonder Haar TH, Stephens GL, Ringerud MA, Combs CL (1996) A new global water vapor dataset. Bull Am Meteorol Soc 77:1233-1246. doi:10.1175/1520-0477(1996) 077<1233:ANGWVD>2.0.CO;2

Rayner NA, Parker DE, Horton EB, Folland CK, Alexander LV, Powell DP, Kent EC, Kaplan A (2003) Global analyses of sea surface temperature, sea ice, and night marine air temperature since the late nineteenth century. J Geophys Res 108:4407. doi: 10.1029/2002JD002670

Reynolds RW, Rayner NA, Smith TM, Stokes DC, Wang W (2002) An improved in situ and satellite SST analysis for climate. J Clim 15:1609-1625. doi:10.1175/1520-0442(2002)015<1609: AIISAS $>2.0 . \mathrm{CO} ; 2$

Rossow WB, Zhang Y-C (1995) Calculation of surface and top of atmosphere radiative fluxes from physical quantities based on ISCCP data sets. Part II: validation and first results. J Geophys Res 100:1167-1197. doi:10.1029/94JD02746

Rossow WB, Schiffer RA (1999) Advances in understanding clouds from ISCCP. Bull Am Meteorol Soc 80:2261-2287. doi:10. 1175/1520-0477(1999)080<2261:AIUCFI >2.0.CO;2

Smith SD (1989) Coefficients for sea surface wind stress, heat flux, and wind profiles as a function of wind speed and temperature. $\mathrm{J}$ Geophys Res 93:15467-15472. doi:10.1029/JC093iC12p15467

Taylor KE (2001) Summarizing multiple aspects of model performance in a single diagram. J Geophys Res 106:7183-7192. doi: 10.1029/2000JD900719

Trenberth KE, Guillemot CJ (1995) Evaluation of the global atmospheric moisture budget as seen from analyses. J Clim 8:22552272. doi:10.1175/1520-0442(1995)008<2255:EOTGAM $>2.0$. $\mathrm{CO} ; 2$

Warren SG, Hahn CJ, London J, Chervin RM, Jenne RL (1988) Global distribution of total cloud cover and cloud type amounts over the ocean. NCAR technical note NCAR/TN-317+STR, 107 $\mathrm{pp}$

Weller B et al (1999) A science and implementation plan for EPIC: an eastern Pacific investigation of climate processes in the coupled ocean-atmosphere system. Available online at http://www. atmos.washington.edu/gcg/EPIC/
Wu T, Wu G (2004) An empirical formula to compute snow cover fraction in GCMs. Adv Atmos Sci 21:529-535. doi:10.1007/ BF02915720

Wu T, Yu R, Zhang F (2008) A modified dynamic framework for atmospheric spectral model and its application. J Atmos Sci 65:2235-2253. doi:10.1175/2007JAS2514.1

Xie P, Arkin PA (1996) Analyses of global monthly precipitation using gauge observations, satellite estimates, and numerical model predictions. J Clim 9:840-858. doi:10.1175/15200442(1996)009<0840:AOGMPU>2.0.CO;2

Yan H (1987) Design of a nested fine-mesh model over the complex topograph, Part two: parameterization of the subgrid physical processes. Plateau Meteorol 6(suppl):64-139

Yu Y, Zhang X (1998) A modified monthly flux anomaly scheme for coupling an AGCM and an OGCM. Chin Sci Bull 43:866-870

Zhang GJ, McFarlane NA (1995) Sensitivity of climate simulations to the parameterization of cumulus convection in the Canadian Climate Centre general circulation model. Atmos Ocean 33:407446

Zhang GJ, Mu M (2005a) Effects of modifications to the ZhangMcFarlane convection parameterization on the simulation of the tropical precipitation in the National Center for Atmospheric Research Community Climate Model, version 3. J Geophys Res 110:D09109. doi:10.1029/2004JD005617

Zhang GJ, Mu M (2005b) Simulation of the Madden-Julian oscillation in the NCAR CCM3 using a revised ZhangMcFarlane convection parameterization scheme. J Clim 18:4046-4064. doi:10.1175/JCLI3508.1

Zhang PQ, Li QQ, Wang LN, Liu YM, Shi XL, Wu TW (2004a) Development and application of dynamic climate model prediction system in China. Sci Technol Rev 7:17-20 (in Chinese)

Zhang YC, Rossow WB, Lacis AA, Oinas V, Mishchenko MI (2004b) Calculation of radiative fluxes from the surface to top of atmosphere based on ISCCP and other global data sets: refinements of the radiative transfer model and the input data. J Geophys Res 109:D19105. doi:10.1029/2003JD004457

Zeng X, Zhao M, Dickinson RE (1998) Intercomparison of bulk aerodynamic algorithms for the computation of sea surface fluxes using TOGA COARE and TAO data. J Clim 11:2628-2644. doi:10.1175/1520-0442(1998)011<2628:IOBAAF>2.0.CO;2 